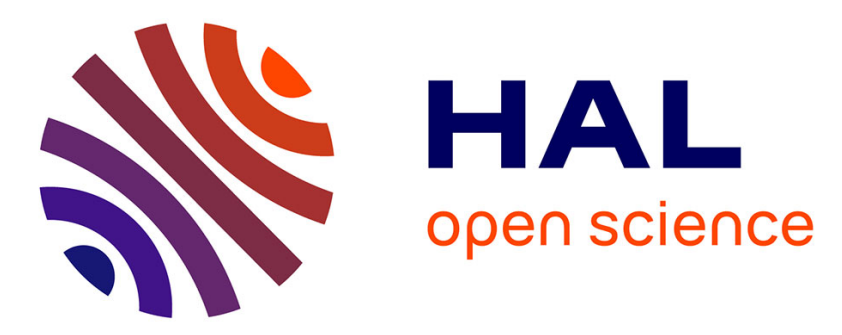

\title{
Azacalixquinarenes: From Canonical to (Poly-)Zwitterionic Macrocycles
}

Simon Pascal, Lucien Lavaud, Cloé Azarias, Alexandre Varlot, Gabriel Canard, Michel Giorgi, Denis Jacquemin, Olivier Siri

\section{- To cite this version:}

Simon Pascal, Lucien Lavaud, Cloé Azarias, Alexandre Varlot, Gabriel Canard, et al.. Azacalixquinarenes: From Canonical to (Poly-)Zwitterionic Macrocycles. Journal of Organic Chemistry, 2019, 84 (3), pp.1387-1397. 10.1021/acs.joc.8b02847 . hal-02003222

\section{HAL Id: hal-02003222 \\ https://hal.science/hal-02003222}

Submitted on 31 Jan 2020

HAL is a multi-disciplinary open access archive for the deposit and dissemination of scientific research documents, whether they are published or not. The documents may come from teaching and research institutions in France or abroad, or from public or private research centers.
L'archive ouverte pluridisciplinaire HAL, est destinée au dépôt et à la diffusion de documents scientifiques de niveau recherche, publiés ou non, émanant des établissements d'enseignement et de recherche français ou étrangers, des laboratoires publics ou privés. 


\title{
Azacalixquinarenes: from Canonical to (Poly-)Zwitterionic Macrocycles
}

\author{
Simon Pascal, ${ }^{*}$, Lucien Lavaud $^{\dagger}{ }^{\text {Cloé Azarias, }},{ }^{\ddagger}$ Alexandre Varlot, ${ }^{\ddagger}$ Gabriel Canard, ${ }^{\dagger}$ Michel \\ Giorgi, ${ }^{\S}$ Denis Jacquemin, ${ }^{* \neq}$ and Olivier Siri ${ }^{*} \dagger$ \\ † Aix Marseille Université, CNRS UMR 7325, CINAM, Campus de Luminy, case 913, 13288 Marseille cedex o9, France \\ ‡ Laboratoire CEISAM, CNRS UMR 6230, Université de Nantes, 2, rue de la Houssinière, 44322 Nantes, France \\ $\S$ Fédération des Sciences Chimiques de Marseille-Spectropole, FR 1739 Aix-Marseille Université, 13397 Marseille, \\ France
}

\begin{abstract}
Azacalixquinarenes, a new family of macrocycles constituted of diaminobenzoquinone diimine units linked by dinitrobenzene rings are synthesized by selected oxidation of the parent azacalixarenes. Crystallographic analyses of two compounds demonstrated the presence of (uncharged) canonical and zwitterionic quinones within a single structure. The electron-withdrawing nature of the dinitrobenzene moieties can trigger the intramolecular H-transfer that generates zwitterionic-ground state quinones. The nature of the $\mathrm{N}$ substituents and the polarity of the solvent have a crucial impact on the equilibrium between the canonical and zwitterionic

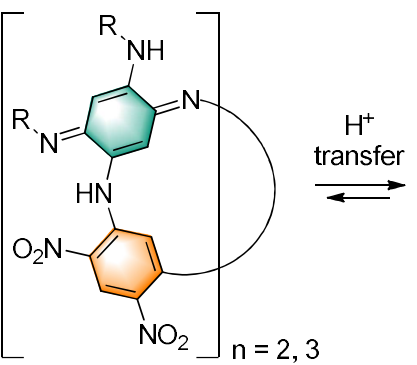

canonica

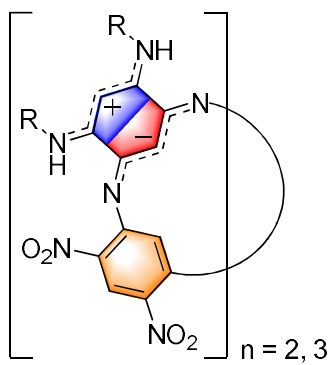

(poly-)zwitterionic

forms that present distinct optical and electrochemical properties. Thus, within [4]- and [6]-membered macrocycles, poly-zwitterionic structures can be reached, as demonstrated experimentally and theoretically using first-principle approaches.
\end{abstract}

\section{INTRODUCTION}

Heteroatom-bridged calixarenes are an evolved class of calixarene macrocycles ${ }^{1,2}$ in which the introduction of a bridging heteroatom in lieu of a methylene link provides additional features such as: (i) the tuning of the cavity size and of the conformation (e.g. 1,3-alternate structure); (ii) new redox properties; and (iii) conjugation between the units of the macrocyclic oligomer. ${ }^{3,4}$ Beyond the wide range of heteroatom-containing calixarenes developed during the past decades, azacalixarenes (ACA) demonstrated an undeniable versatility regarding structure-properties shaping. ${ }^{5}$ Since seminal works in the late nineties on polyazacalixarenes, ${ }^{6-10}$ this family has been growing to incorporate trypticene moieties, ${ }^{11,}{ }^{12}$ pyridine units, ${ }^{13,14}$ and covalently-bonded metallic centers conferring unusual reactivity. ${ }^{15-20}$ Noteworthy, ACA macrocycles were valorized for carbon dioxide uptake, ${ }^{21,22}$ fullerene or anions complexation ${ }^{23-25}$ and demonstrated to be relevant as hole- and spin-containing architectures. ${ }^{26,27}$ In 2013, the azacalixphyrin (ACP, Figure 1) was reported as the only known "azacalixarene-like" derivative introducing four oxidized tetraaminobenzene units that promote a stable bis-zwitterionic ground electronic state. ${ }^{28-33}$ Consequently ACP can be viewed as a masked conjugated azacalixquinone. Its aromatic core involving $18 \pi$-electrons confers to the ACP a strong absorption $c a$. $900 \mathrm{~nm}$ that can be tuned by substitution of the peripheral imine functions (Figure $1, \mathrm{R}=\mathrm{H}$, aryl, alkyl). ${ }^{30,34}$ 


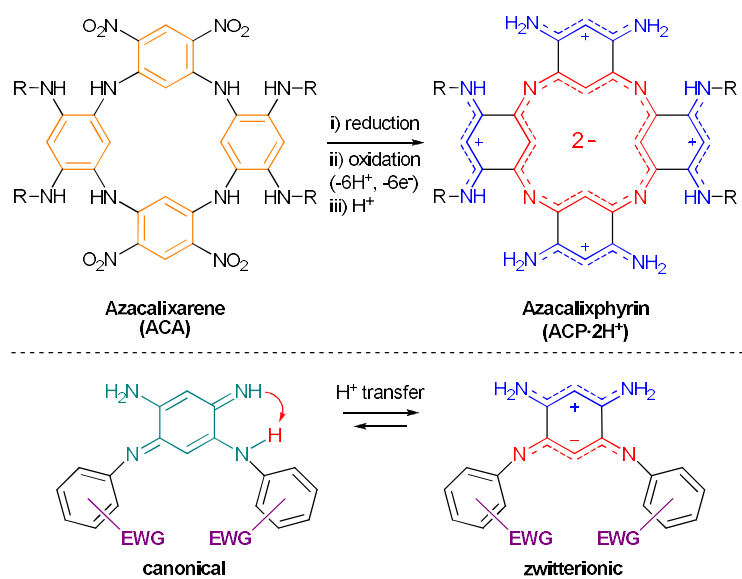

Figure 1. Previously reported azacalixphyrin macrocycle (top) and illustration of the canonical-zwitterionic equilibrium in 2,5diaminobenzoquinone diimines (bottom).

Chart 1. Scope of the study (only the canonical form is represented).

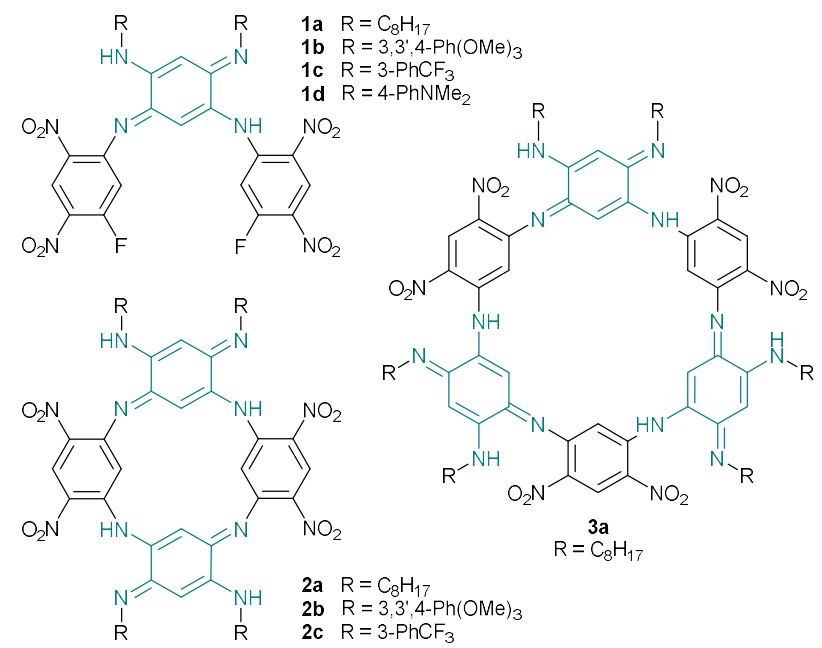

Interestingly, we recently reported that the constituting unit of ACP, the monocyclic 2,5-diamino benzoquinone diimine, can be also stabilized under a zwitterionic ground state if it is functionalized with strongly electron-withdrawing aromatic substituents (EWG, Figure 1). ${ }^{35}$ In the case of quinone 1a featuring 5-fluoro-2,4-dinitrophenyl moieties (Chart 1), the zwitterionic form was found to dominate in both solution and solid states. 
With the aim to combine several of these systems in a single molecule and study the impact on the canoni$\mathrm{cal} /$ zwitterionic equilibrium, we naturally focused our attention on the elaboration of macrocyclic architectures of types 2 or 3 presenting an alternation of quinones and aromatic rings substituted with EWG. We report herein their synthesis from ACA precursors and demonstrate that these macrocycles (2a-c and 3a), named azacalixquinarenes (ACQ), can be seen as "hemi-azacalixphyrins", i.e. an intermediary class of ACA-ACP derivatives featuring an alternation of dinitrosubstituted aromatic rings and diaminobenzoquinone diimine rings. As for model compounds 1a-d, the quinoidal fragments within ACQs can be either stabilized under canonical (uncharged) or zwitterionic forms depending on given parameters ( $N$-substituents, solvent), allowing to reach unprecedented poly-zwitterionic systems.

\section{RESULTS AND DISCUSSION}

Synthesis. The access to the target ACQs 2a-c was envisaged by chemical oxidation of the azacalix[4]arene precursors (Scheme 1). Therefore, the preparation of ACA 7a-c was carried out following a well-established strategy starting from precursors $\mathbf{4 a - c}$, incorporating octylamine or selected aniline moieties, which were reduced under acidic conditions in presence of $\mathrm{Sn}$ (II) salts or Fe powder, then substituted by 1,5-difluoro-2,4-dinitrobenzene (DFDNB) to afford the adducts 6 a-c. ${ }^{30,34}$

Scheme 1. Synthesis of compounds 1a-d, za-c and za (quinones only represented under their canonical forms).
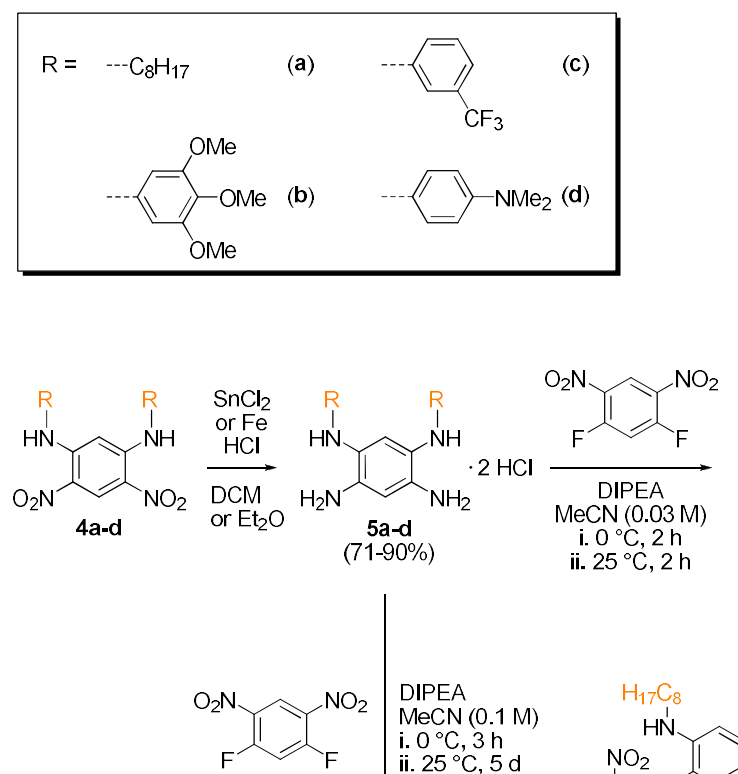

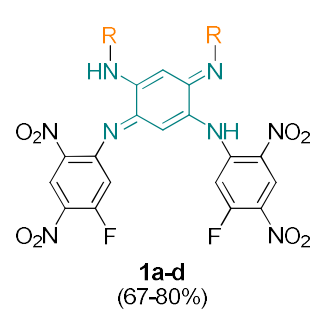

$\uparrow \begin{aligned} & \mathrm{DDQ}, \mathrm{CHCl}_{3} \\ & 25^{\circ} \mathrm{C}, 30 \mathrm{~min}\end{aligned}$

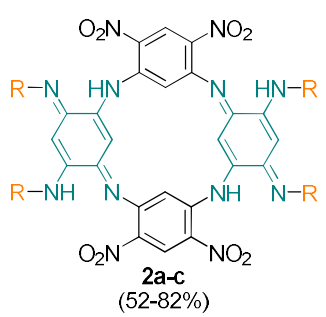

$\left\{\begin{array}{l}\mathrm{DDQ}, \mathrm{CHCl}_{3} \\ 25^{\circ} \mathrm{C}, 1 \mathrm{~h}\end{array}\right.$

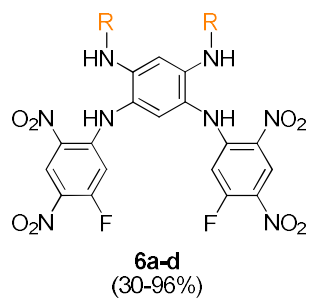
$6 \mathrm{a}-\mathrm{d}$
$(30-96 \%)$

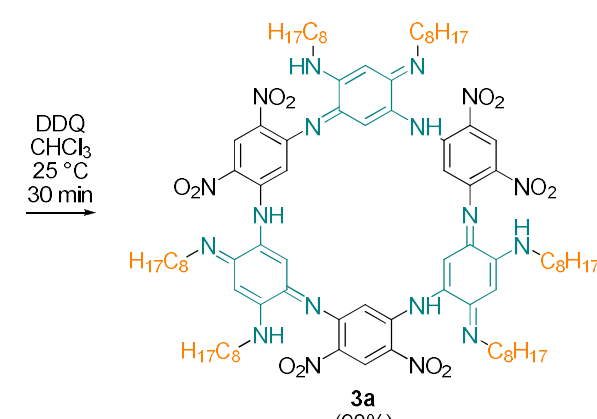

These intermediates were converted to the corresponding azacalix[4]arene $\mathbf{7 a - c}$ using one equivalent of tetraaminobenzenes $\mathbf{4 a - c}$ in refluxing acetonitrile. For compound $\mathbf{6 d}$, previously unknown, the reaction was carried out at room temperature and a low concentration of ${ }_{5} \mathbf{d}\left(10^{-2} \mathrm{M}\right)$ was necessary to reach a moderate yield (43\%, Table $\left.\mathrm{S} 1\right)$. Such poor efficiency is presumably imputable to a lack of regioselectivity during the nucleophilic aromatic substitution of the electron-rich adduct ${ }^{\mathbf{d}} \mathbf{d}$ on DFDNB. Unfortunately, for the same reason, it was impossible to reach the corresponding azacalix[4]arene 6d using classical conditions. The synthesis of azacalix[6]arenes 8a was more straightforward and allowed the isolation of the macrocycle in only one step from octylamine-decorated tetraaminobenzene $\mathbf{5}$ a, with however a poor $5 \%$ yield. ${ }^{24}$ Note that the formation of higher order macrocycles was not observed. 
As expected, series of azacalix[4]arenes $\mathbf{7 a - c}$ and azacalix[6]arene $\mathbf{8 a}$ could be oxidized to the corresponding azacalixquinarenes 2a-c and 3 a using 2 and 3 equivalents of 2,3-dichloro-5,6-dicyano-1,4-benzoquinone (DDQ), respectively. The reaction proceeded rapidly, nevertheless purification was more tedious for aryl-substituted quinones $\mathbf{2 b}-\mathbf{c}$ which revealed a poor solubility in organic solvents. In contrast, macrocycles $2 \mathbf{a}$ and $\mathbf{3 a}$, featuring octyl chains, show a surprisingly good solubility in dichloromethane and were obtained in $82 \%$ and $90 \%$ yields, respectively. Eventually, care was taken to verify that the ACQ 2 a could be converted to the corresponding ACP by reducing the nitro functions in presence of $\mathrm{Pd} / \mathrm{C}$ and excess hydrazine in refluxing tetrahydrofuran for 2 days. Following a classical workup and overnight aerial oxidation, the expected bis-zwitterionic ACP-C8 (Figure 1, ACP with $\mathrm{R}=\mathrm{C}_{8} \mathrm{H}_{17}$ ) was isolated in a 97\% yield (see Experimental Section for details).

With the perspective to study them as model compounds, the quinone 1a-d were prepared from the aromatic derivatives 6a-d, following their treatment with a stoichiometric amount of DDQ in degassed chloroform. ${ }^{35}$ The compounds were conveniently purified either by precipitation or by flash column chromatography and finally isolated with good yields (67$80 \%)$.

Structural analysis. X-ray quality crystals could be obtained for quinone $\mathbf{1 b}$ by slow evaporation of an acetonitrile solution. All H-atoms were found experimentally for $\mathbf{1 b}$, as well as the $\mathrm{H}$-atoms for the central cycles and amines in 2a and za, except the one for amine N6 in za (see Figure 4) that was introduced at geometrical position. Unlike the previously reported crystal structure of $\mathbf{1 a}$, featuring a zwitterionic ground state, ${ }^{35}$ the molecule $\mathbf{1 b}$ presents an alternation of single and double bonds in both subunits of the quinoidal ring (BLA ca. o.10 A; Figure 2). Thus, the presence of slightly electron-donating aromatic substituents in $\mathbf{1 b}$ promotes an unequivocal canonical ground state. This unexpected result, which helps to rationalize the optical properties of ACQ $\mathbf{2 b}$ (see below), is consistent with theoretical predictions and experimental evidences that aryl-substituted ACPs tend to stabilize canonical tautomers due to the extent of delocalization brought by the aryl substituents. ${ }^{31,34}$

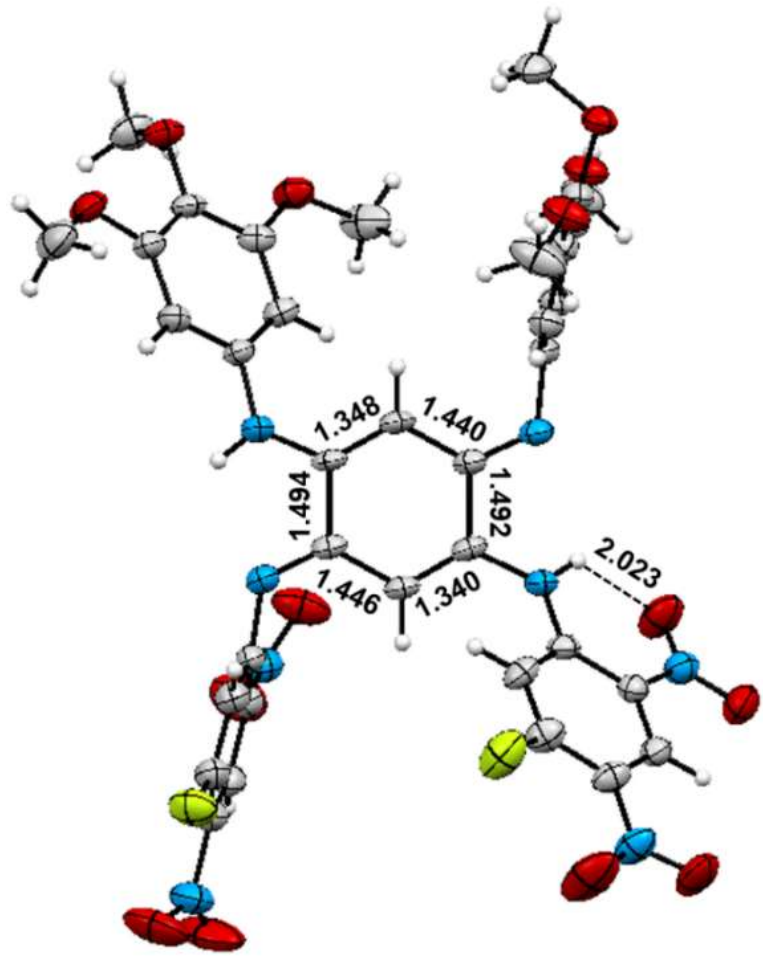

Figure 2. Single crystal structures of canonical $\mathbf{1 b}$ with selected bond lengths $(\AA ̊)$. Anisotropic displacement ellipsoids plot at the 50 percent probability level.

Single crystals of $\mathbf{2 a}$ were obtained from a dichloromethane-acetonitrile solution and the structure is presented in Figure 3. Considering the striking effect of the environment on the ground state structure of the ACQs (vide infra), it is worth to underline that crystals of 2 a obtained from acetone or dimethylformamide solutions gave rise to the exact same structure and packing. An unusual solid-state structure is evidenced for this ACQ corresponding to the mixed form zc-2a (Scheme 2), which presents two aromatic dinitrobenzene moieties binding two oxidized rings, one of them being a zwitterion structure, the other being a canonical structure. The former ring is characterized by two $6 \pi$-electrons subunits, one cationic and the other anionic, linked by single bonds (1.50 $\AA$ ). Within each cyanine systems, the bond length alternation nearly vanishes (BLA ca. $0.01 \AA$ ) due to the strong delocalization of the charges along the trimethine motifs. Surprisingly, 
for both oxidized rings, the two $6 \pi$-electrons subsystems are not belonging to the same plane, with an angle of $6^{\circ}$ for the zwitterionic system and $4^{\circ}$ for the canonical one. One can notice that the presence of these two quinone rings within ACQ $3 a$ also induces a strong distortion of the 1,3-alternate configuration, compared to parent analogous ACA structures. ${ }^{36}$ The only acidic hydrogen atom borne by the macrocyclic core is involved in a $1.98 \AA$ A hydrogen bond with one of the peripheral nitro function. The distance between the two oxidized ring centroids is $6.86 \AA$, this value being close to the one found in unsubstituted ACP $(6.65 \AA)$ and standing out from classical 1,3-alternate ACA 7a, which presents a distance of $4.74 \AA$ between the two octyl- substituted aromatic rings. ${ }^{24}$ The angle formed between the two planes of the quinone rings is ca. $110^{\circ}$, which is comparable to the data measured for unsubstituted ACP (see Table S3).
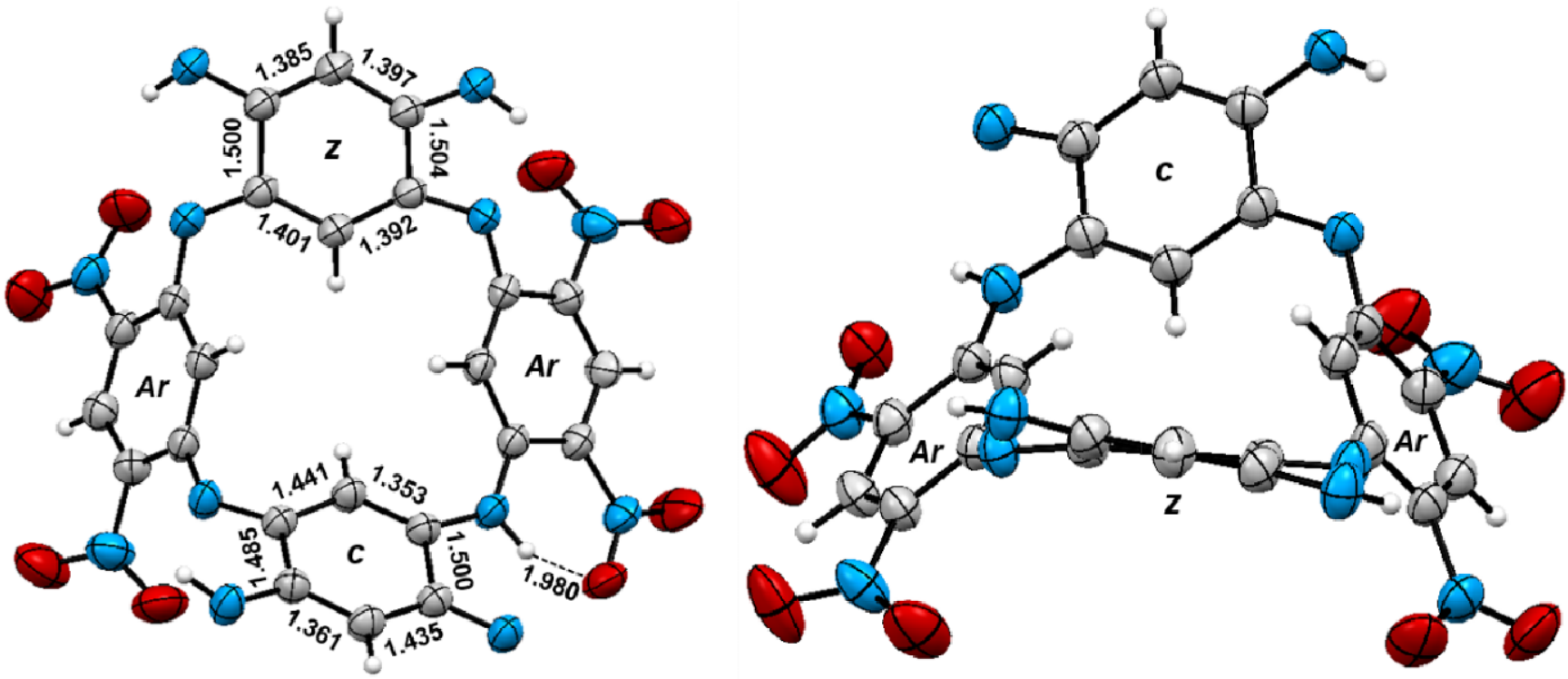

Figure 3. Single crystal structure of 2a. Selected bond lengths $(\AA)$ and the electronic structure of each rings are indicated: zwitterionic (z), canonical (c) and aromatic $(\boldsymbol{A r})$. N-octyl chains are omitted for clarity. Anisotropic displacement ellipsoids plot at the 50 percent probability level.

Scheme 2. Possible H-transfers and tautomeric structures of series 1a-d, azacalix[4]quinarenes $2 a-c$ and azacalix[6]quinarene za. $c$ and $z$ stand for canonical and zwitterionic, respectively. Note that only one structure for compounds containing at least one $\mathrm{c}$ unit is shown here but other (generally less stable) tautomers can be drawn, see Schemes $S_{1}, S_{2}$, and $S_{3}$ in the ESI.
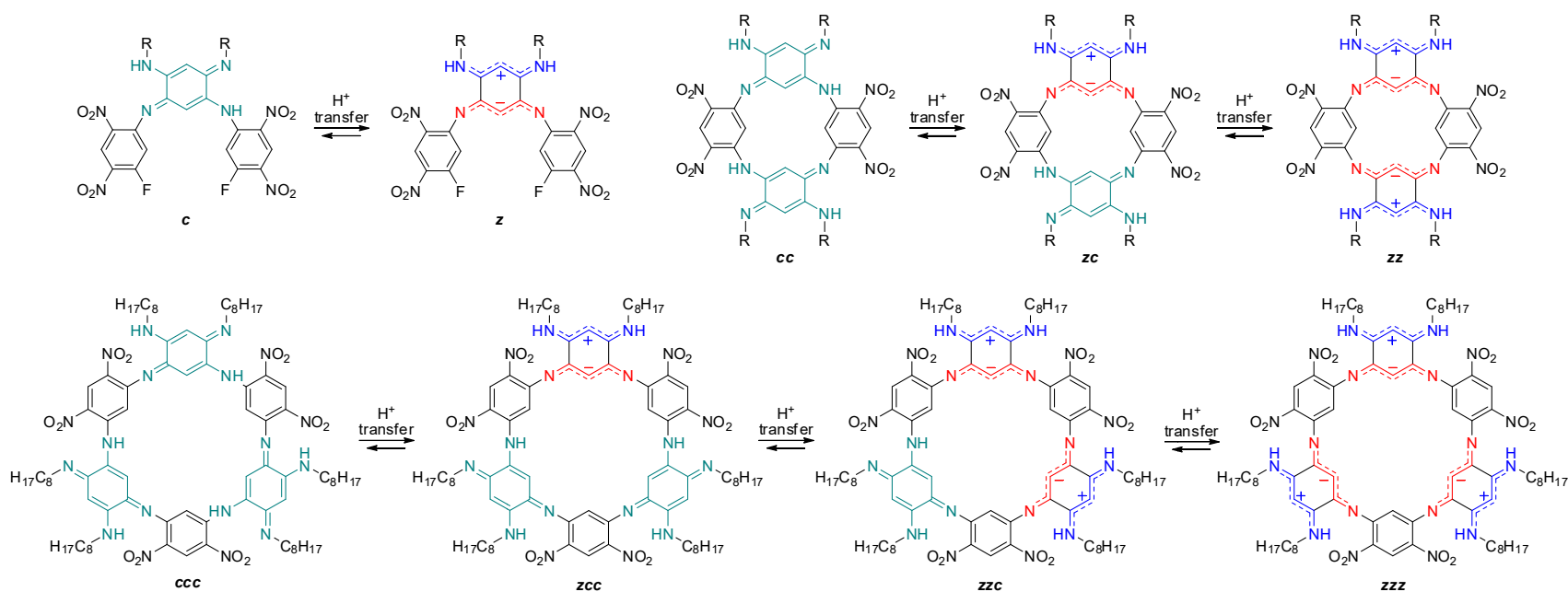

Finally, ACQ za was crystallized from evaporation of a solution in acetone and stands as one of the rare example of six-membered azacalix-derivatives (Figure 4). ${ }^{13,14,21,23,24,37,38}$ The structure reveals that 3 a crystallizes with two independent molecules in the asymmetric unit that stack together through two $\pi-\pi$ ring interactions between, on one hand, two of their canonical $c$ cycles and, on the other hand, two of their aromatic cycles. Indeed the distance between the cen- 
troids is equal to 4.359(4) $\AA$ between the canonical cycles and 4.270(4) A between the aromatic ones, while the dihedral angles are equal to $7.5(3)^{\circ}$ and $1.6(3)^{\circ}$ respectively. The slippage between the centroids is equal to $2.443 \AA$ and $2.497 \AA$ for the canonical and the aromatic rings respectively. In both independent molecules the macrocycle presents three aromatic dinitrobenzene moieties, two canonical quinones and one zwitterionic ring, thus corresponding to the structure zcc-3a in Scheme 2. It is worthy to note that both acidic hydrogen atoms $(\mathrm{NH})$ borne by the central core are symmetrically distributed and involved in H-bonds with the closest nitro functions. The 1,2,4,5-alternate structure (u,d,d,u,d,d) is very similar to the parent 8a, with however a distortion brought by the zwitterionic ring. Note that one dinitro aromatic ring is folded inside the cavity and occupies the available space.

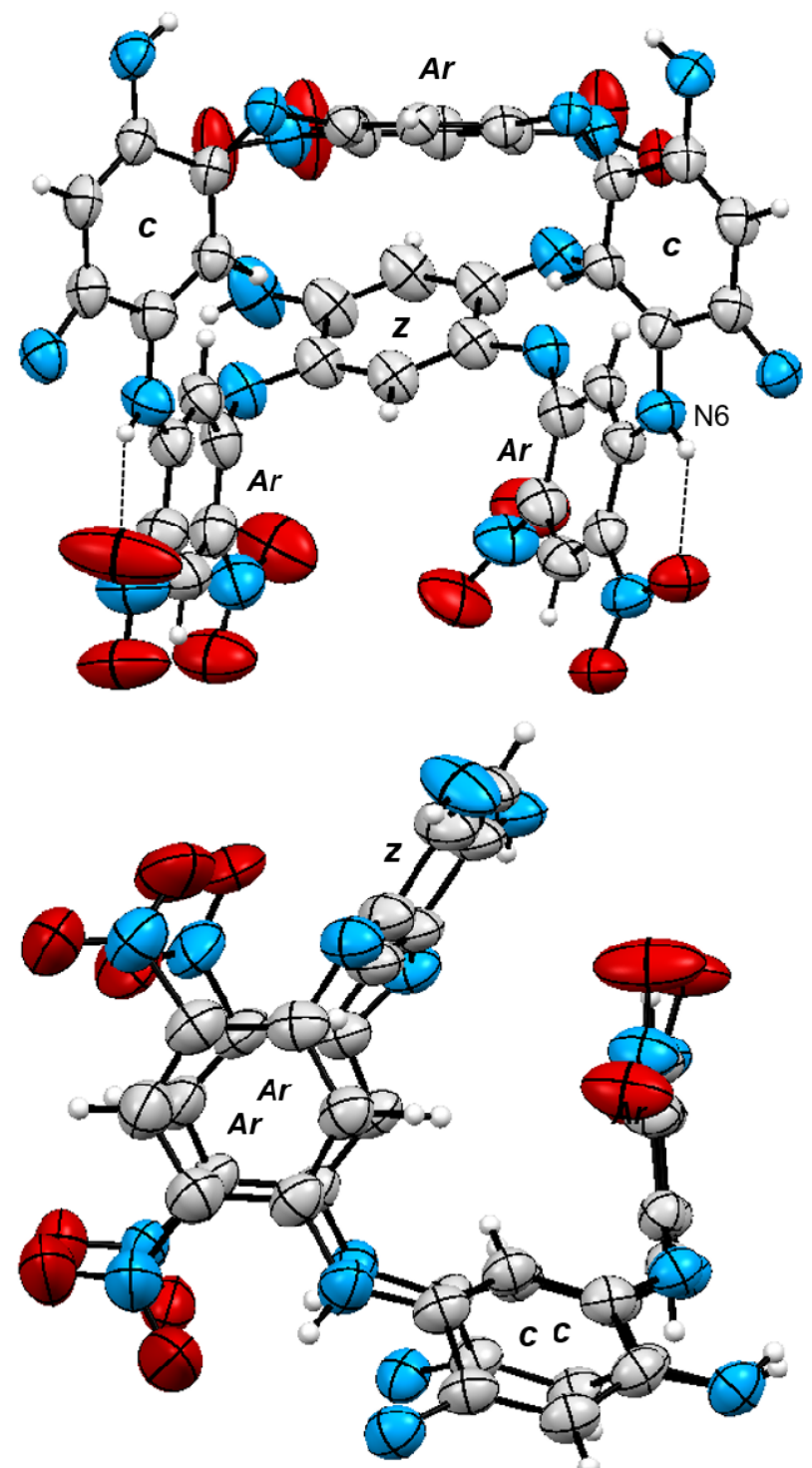

Figure 4. Single crystal structures of $\mathbf{3}$. The electronic structure of each rings are indicated: zwitterionic (z), canonical (c) and aromatic (Ar). $\mathrm{N}$-octyl chains are omitted for clarity. Anisotropic displacement ellipsoids plot at the 50 percent probability level.

Photophysical properties. The electronic absorption spectra of the quinones recorded in acetone solution (ca. $2.10^{-5}$ M) are compiled in Figure 5. As a model compound, alkyl-substituted compound 1a exhibits a characteristic broad absorption band centered at $c a$. $700 \mathrm{~nm}$, which is the fingerprint of the zwitterionic form $\mathbf{z}-\mathbf{1 a}$. This transition is attributed to an intramolecular charge transfer (ICT) from the anionic trimethine to the cationic one (cyanine-to-cyanine ICT), its intensity depending on the proportion of ground-state zwitterion in solution. ${ }^{35}$ This analysis is corroborated by theoretical calculations (see Figure $S_{34}$ and Table S9 in the ESI). Quinones $\mathbf{1 b}$ and $\mathbf{1 c}$, which possess trimethoxyaniline and $m$ trifluoromethylaniline moieties do not present such transition, which hints at a prominent canonical ground-state for these compounds, the strong UV band and its tail in the visible region being classical features of tetra-substituted diamino benzoquinone diimines. ${ }^{39}, 4^{\circ}$ In contrast, the absorption of $p$-dimethylaminoaniline-substituted $\mathbf{1 d}$ shows a panchromatic absorption spanning from 400 to $800 \mathrm{~nm}$. Two main transitions can be identified at 654 and $570 \mathrm{~nm}$, and are counter-intuitively theoretically attributed to the forms $\boldsymbol{c}$-1d and $\mathbf{z}$-1d, respectively (vide infra). In any case, this result 
underlines that, for aniline substituted quinones $\mathbf{l b}$-d, very electron-rich auxochromes are needed to trigger the proton transfer and subsequently observe the presence of the zwitterion. The solvatochromism of this series has been recorded in different solvents ranging from toluene to DMSO and shows a very low impact on the absorption of canonical compounds $\mathbf{1 b}-\mathbf{c}$, while a moderate hyperchromic effect is observed for $1 \mathbf{a}$ and $\mathbf{1 d}$ in solvent of high polarity due to the generation of the zwitterionic forms (Figure S30).

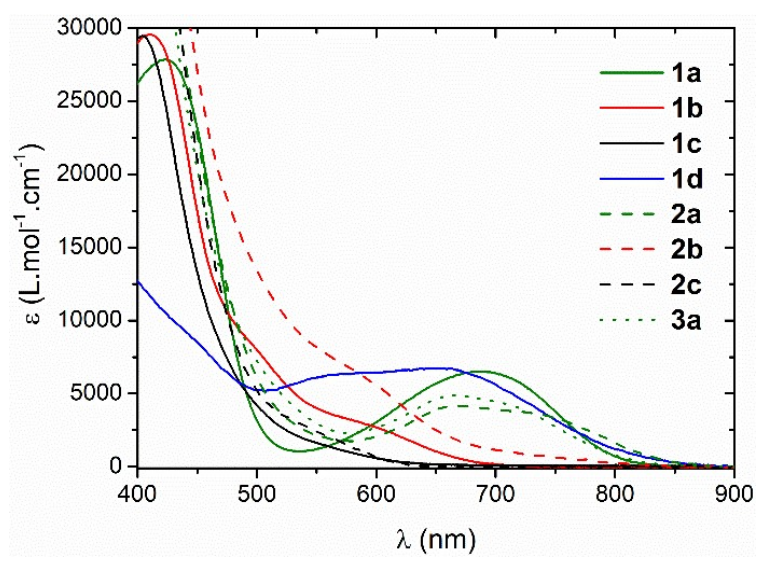

Figure 5. Electronic absorption spectra of the quinones in acetone.

The absorption solvatochromism of the macrocycle $\mathbf{2 a}$ is particularly interesting since a strong evolution of the lower energy transition is monitored depending on the solvent (Figure 6). Going from toluene to dichloromethane solution, the molar extinction coefficient increases from $c a .720$ to $4200 \mathrm{M}^{-1} . \mathrm{cm}^{-1}$. In acetone, a transition centered at $660 \mathrm{~nm}$ starts to emerge and ultimately becomes the most intense band in DMSO $\left(\varepsilon=6800 \mathrm{M}^{-1} \cdot \mathrm{cm}^{-1}\right)$. With the help of theory (Figure S46 and Table S16 in the ESI), the hyperchromic shift in the less polar solvents compared to z-1a is attributed to the stronger absorbance of zc-2a in solution (tripling of the oscillator strength compared to 1a), while the growing blueshifted transition corresponds to the bis-zwitterionic zz-2a. In a different way, the ACQ $\mathbf{2 b}$ presents characteristic "canonical-type" absorption spectra with negligible differences in the range of solvents screened. In contrast, the macrocycle $\mathbf{2 c}$ shows the apparition of a band at $700 \mathrm{~nm}$ in the most polar solvents such as DMF and DMSO $\left(\varepsilon=4200 \mathrm{M}^{-1} \cdot \mathrm{cm}^{-1}\right)$. Such behavior is tentatively assigned to the formation of mixed species zc-2c following intramolecular proton transfer in the corresponding bis-canonical macrocycle. Finally, the [6]-membered macrocycle za exhibits a very similar progression of absorption that of $\mathbf{2 a}$. The broad transition at ca. 650-700 $\mathrm{nm}$ observed in toluene and dioxane potentially implies the presence of at least one zwitterionic quinone among the three oxidized rings of za (see tautomer zcc-3a in Figure 4 and Scheme 2). The growing transition noticed in DMSO is most probably due to the evolution towards species zzc-3a and/or zzz-3a (see calculations below).
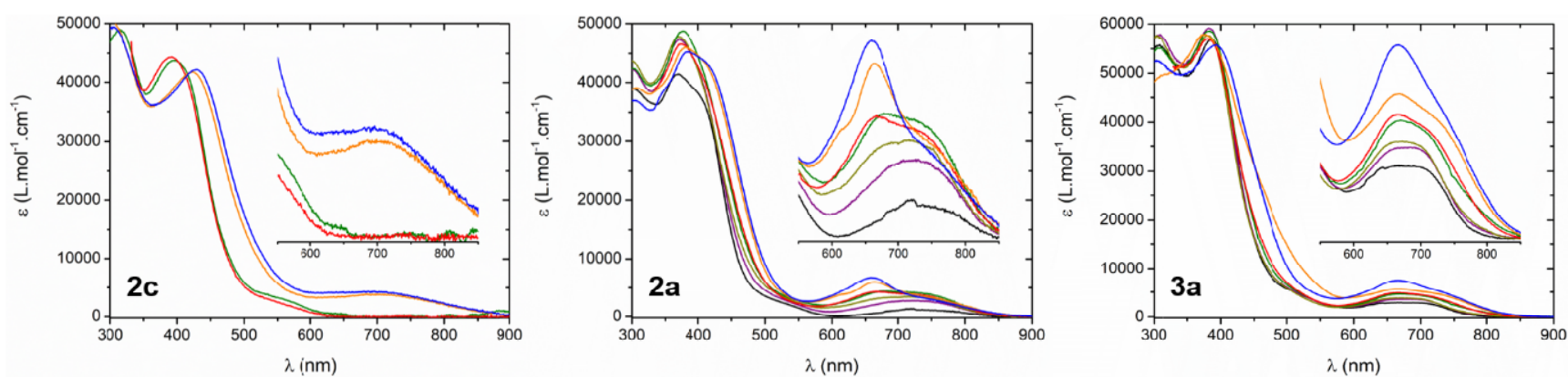

Figure 6. UV-Vis-NIR absorption solvatochromism of $\mathbf{2 c}$, 2 a and $3 \mathbf{a}$ in toluene (-), 1,4-dioxane (-), ethyl acetate (-), dichloromethane (-), acetone (-), N,N-dimethylformamide (-) and dimethylsulfoxide (一).

Cyclic voltammetry. The redox properties of compounds 1a-d, 2a-c and $3 \mathbf{a}$ were analyzed by recording their cyclic voltammograms $(\mathrm{CV})$ in DCM and in DMF solutions (containing $0.1 \mathrm{M}$ of $\left[\left({ }^{n} \mathrm{Bu}_{4} \mathrm{~N}\right) \mathrm{PF}_{6}\right]$ and using ferrocene as an internal standard (Figures S28 and S29). The corresponding oxidation and reduction half-wave potential $\mathrm{E}_{1 / 2}$ values are given versus the oxidation potential of ferrocene and are listed in Table $\mathrm{S}_{4}$. In DCM, each CV features up to three irreversible reduction waves and up to two oxidation ones. In DMF, no oxidation potential values of compounds $\mathbf{1 c}$ and $\mathbf{2 c}$ are reported since these processes are occurring out of the solvent electro-chemical window. 
For the 1a-d series, the first reduction processes centered on the most electron-accepting di-nitro-fluorobenzene moieties have $\mathrm{E}_{1 / 2}$ values that are not strongly affected by the nature of the $N$-substituents nor by the solvent polarity. For example, in both solvents, the replacement of the electron-withdrawing $m$-trifluoromethylphenyl groups of $\mathbf{~ i c ~ b y ~ e l e c t r o n - d o n a t i n g ~}$ p-dimethylaminophenyl ones in $\mathbf{1 d}$ induces a cathodic shift of the first reduction wave by less than $50 \mathrm{mV}$. In contrast, in the four membered macrocycle 2a-c series, where the fluorine atoms have been replaced by tetraaminobenzoquinone moieties, such variation of the $N$-substitution has a noticeable effect on the first reduction $\mathrm{E}_{1 / 2}$ values. For example, the first reduction waves located at $-1.06 \mathrm{~V}(\mathrm{DCM})$ and $-1.00 \mathrm{~V}(\mathrm{DMF})$ for $2 \mathrm{a}$ (Figure 7) are found at $-0.78 \mathrm{~V}(\mathrm{DCM})$ and at $0.84 \mathrm{~V}(\mathrm{DMF})$ when studying 2c. The first oxidation potential values are significantly affected by the nature of the $N$ substituents and/or by the solvent polarity. For example, in DCM, when going from $\mathbf{1 b}$ and $\mathbf{2 b}$ to $\mathbf{1 c}$ and $\mathbf{2 c}$, the increasing electron-accepting strength of the $N$-substituents produces an anodic shift of the first oxidation wave by more than 250 $\mathrm{mV}$. The variation of the first oxidation $\mathrm{E}_{1 / 2}$ value with the solvent polarity can also be used as an additional proof of the occurrence of a canonical/zwitterionic balance. Indeed, if the solvent polarity has a limited impact on the location of the oxidation of the canonical $\mathbf{1 b}$ and $\mathbf{2} \mathbf{b}$ compounds, it induces, for the oxidation $\mathrm{E}_{1 / 2}$ values of compounds $\mathbf{1 a}$, $\mathbf{2 a}$ and $\mathbf{3 a}$, a significant variation of more than $150 \mathrm{mV}$. This canonical/zwitterionic equilibrium is probably responsible for the decrease of the electrochemical gaps $(\geq 200 \mathrm{mV})$ of $\mathbf{1 a}, \mathbf{2 a}$ and $3 \mathbf{a}$ when changing DCM by DMF (Figure 7 ), while those of $\mathbf{1 b}$ and $\mathbf{2} \mathbf{b}$ are only slightly affected $(\leq 50 \mathrm{mV})$.

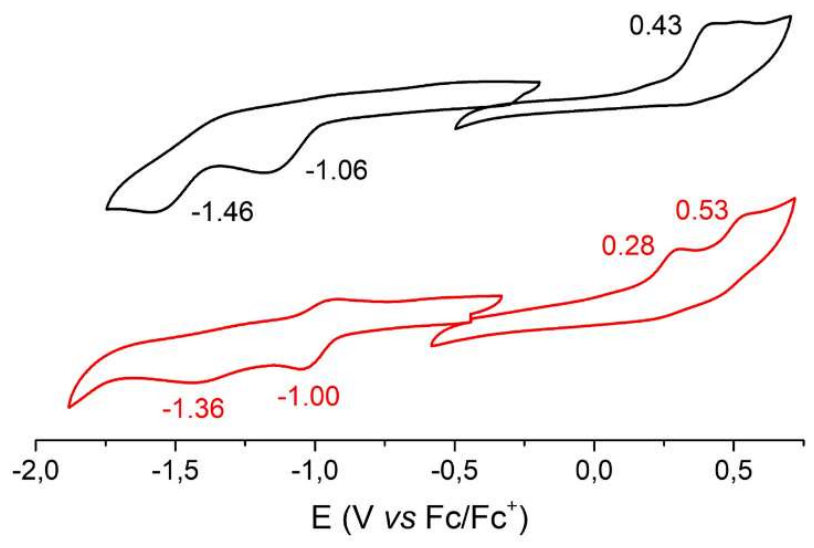

Figure 7. Cyclic voltammograms of compound 2a in DCM (black) and DMF (red) solutions.

Theoretical calculations. In order to obtain further insights into the underlying electronic structures and evaluate the relative stabilities of the various tautomers, DFT and TD-DFT calculations have been performed on all the systems studied herein. Let us first compare the crystallographic structures with the one modelled in gas phase for $\mathbf{1 b}$, 2a, and $\mathbf{3 a}$. For the two former compounds, we have performed a full tautomeric search, i.e., modelling not only structures presenting rings of $\mathbf{z}$ and/or $\mathbf{c}$ forms (displayed in Scheme 2), but also accounting for other possible types of rings (see Schemes $\mathrm{S} \mathbf{1}$ and $S_{2}$ in the ESI). For $\mathbf{1 b}$, among the four tautomers considered, theory predicts that the canonical $\boldsymbol{c}$ form is the most stable by more than $2 \mathrm{kcal}^{\mathrm{mol}} \mathrm{l}^{-1}$ compared to the other forms, which is in perfect agreement with the X-ray structure. One notices that the $\boldsymbol{a}$ and $\boldsymbol{x}$ tautomers (see the ESI for representation) are much less stable (>10 kcal.mol ${ }^{-1}$, Table $\left.\mathrm{S}_{5}\right)$ than the $\mathbf{z}$ and $\mathbf{c}$ structures, which is also consistent with our previous work on a similar compound..$^{35}$ The BLA determined for $\mathbf{c}-\mathbf{1 b}$ is ca. $0.07 \AA$, only slightly smaller than in the XRD (vide supra). For 2a, among the thirteen different tautomers considered, it turns out that the macrocycles presenting a least one ring of type $\boldsymbol{a}$ or $\boldsymbol{x}$ are very unlikely with relative free ener-

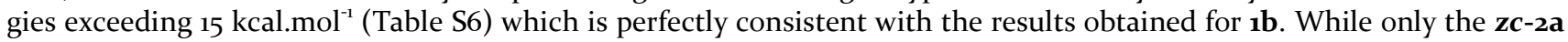
structure has been evidenced experimentally, theory predicts that the cc structure is slightly more stable than zc. However, the computed difference (1 kcal.mol $\left.{ }^{-1}\right)$ is within DFT error bar and could be overcome by crystal packing effects, not accounted for in the calculations. In zc-2a, the DFT determined CC bond lengths in the zwitterionic cycle are 1.386 and $1.389 \AA$ (external side), and 1.388 and $1.405 \AA$ (internal side), in very good match with the experimental values (Figure 3 ). For 3a, according to the previous observations, only the possible tautomers that combine $\mathbf{z}$ and/or $\mathbf{c}$ type of rings have been taken into account (Scheme $S_{3}$ and Table $S_{7}$ ). Due to its strongly distorted structure, for a given tautomer, several non-equivalent conformers can be drawn and a full conformational search has therefore been performed. It turns out that, in gas phase, only the zcc form in the exact same conformation as the crystallographic structure was found to be stable, the other structures being less stable by at least $3 \mathrm{kcal}^{\mathrm{mol}}{ }^{-1}$.

Let us now turn towards an analysis of the results obtained in solution. We have chosen DMSO as reference solvent except when noted. For $\mathbf{1 a}$, only the $\mathbf{z}$ form, presenting a band at $602 \mathrm{~nm}$ according to TD-DFT (Table S9), is likely to exist in DMSO, the $c$ tautomer being $5 \mathrm{kcal}^{\mathrm{mol}}{ }^{-1}$ less stable. As stated above, this $602 \mathrm{~nm}$ transition involves a significant CT between the two cyanine subunits (Figure S35), consistent with our previous work. ${ }^{35}$ In contrast, for $\mathbf{1 b}$ and $\mathbf{1 c}$, theory finds that the canonical form is preferred by at least $4 \mathrm{kcal}^{\mathrm{mol}} \mathrm{l}^{-1}$ (Tables S1o and S12). The $\mathbf{c}-\mathbf{1 b}$ and $\boldsymbol{c}$-1c compounds pre- 
sent their lowest absorption at 527 and $495 \mathrm{~nm}$, respectively (Figures S36 and S39). There is therefore a clear agreement with the experimental spectra observed for these three species: only the $c$ structures are present and their spectra are blueshifted compared to $\mathbf{z}$-1a. Eventually for $\mathbf{1 d}$, DFT returns almost isoenergetic $\mathbf{z}$ and $\boldsymbol{c}$ tautomers, which are therefore likely to coexist in solution (Table S14). This can explain the broad long-wavelength band obtained in the experimental spectra. Unexpectedly, the absorption band at the longest wavelength is attributed to the $\boldsymbol{c}$-1d $(651 \mathrm{~nm}, f=0.49)$ whereas the first significant absorption of $\mathbf{z}$-1d appears are higher energies ( $540 \mathrm{~nm}, f=0.85$, see Table S15 and Figure S43). This is because the $S_{1}$ state of $\mathbf{z}$-1d, computed at $667 \mathrm{~nm}$ is totally dark. As can be seen in Figures $\mathrm{S}_{41}$ and $\mathrm{S}_{42}$, all the lowest dipole-allowed transitions present a significant CT character, the $p$-amino-phenyl moieties acting as donor groups and the central core acting as acceptor.

For 2a, the free energies and UV-Vis spectra have been calculated in both DCM and DMSO. The results are displayed in the ESI. The computed free energies indicate that the $\boldsymbol{c c}$ forms are not likely to be present in solution $\left(>5 \mathrm{kcal}^{\mathrm{mol}} \mathrm{l}^{-1}\right)$, whereas the difference between the $\mathbf{z c}$ and $\mathbf{z z}$ forms increases when going from DCM to DMSO hinting that the ratio of the latter increases with solvent polarity as expected (Table S16). For both zc and zz, the absorption spectra computed in the two solvents are extremely similar (see Figure $S_{51}$ ), with the first dipole-allowed absorption of $\mathbf{z z}$ appearing at smaller wavelength than the one of zc ( 565 and $621 \mathrm{~nm}$, respectively, see Table S17), for the same reason as in $1 \mathrm{~d}$ (i.e., the first transition in $\mathbf{z z}$ is forbidden). Therefore, the experimentally observed solvatochromism, that is, the increase of the intensity of the blueshifted zwitterionic band when going from DCM to DMSO (see Figure 8), is due to the changes in the relative population of the tautomers rather than a direct solvent effect on their individual spectra. In the zc-2a structure, the band at $621 \mathrm{~nm}$ is clearly centered on the $\mathbf{z}$ cycle (Figure $\mathrm{S}_{4} 8$ ). For $\mathbf{2 b}$, theory predicts that the cc tautomer is the most stable and that the $\mathbf{z z}$ structure is unlikely (relative free energy of $3.8 \mathrm{kcal}^{\mathrm{mol}}{ }^{-1}$, Table Sig) whereas the $\mathbf{z c}$ tautomer is only $1.1 \mathrm{kcal}_{\mathrm{mol}}{ }^{-1}$ above $\mathbf{c c}$. Given the computed spectra (Figure S52), one can therefore probably attribute the small extension of the foot of the band toward the red in $\mathbf{2 b}$ to the formation of a small amount of $\mathbf{z c}$. For $\mathbf{2 c}$, theory predicts that only the $\mathbf{c c}$ exists in solution, the free energies of the other $\mathbf{z c}$ and $\mathbf{z z}$ forms being relatively high, e.g., $3.8 \mathrm{kcal}^{\mathrm{mol}} \mathrm{m}^{-1}$ for $\mathbf{z c}$ (Table S21). This is the only theoretical result not consistent with experiment that returns the presence of zwitterionic forms in the most polar solvents (vide infra).

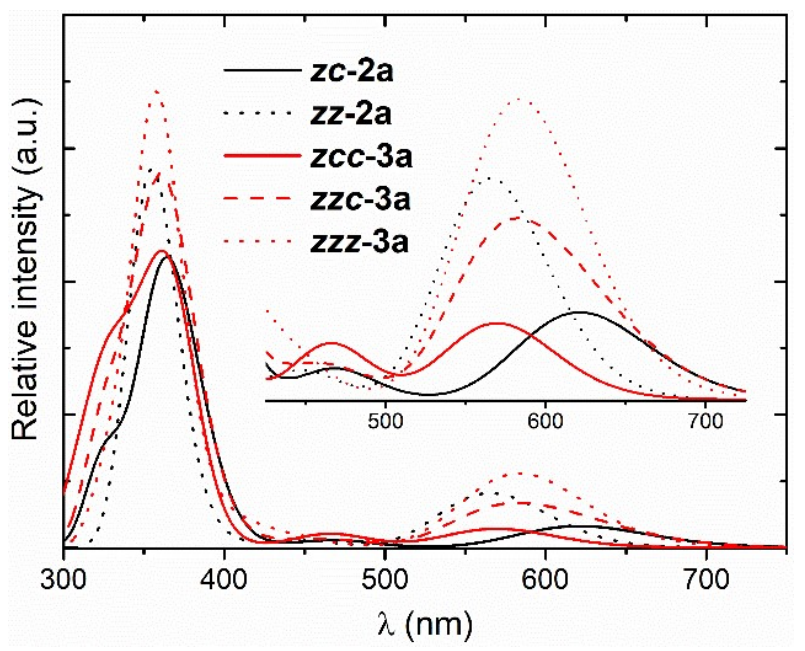

Figure 8. Theoretical absorption spectra of different tautomeric forms of azacalixquinarenes za and za computed in DMSO. The theoretical spectra are obtained using a broadening Gaussian with a FWHM of $2500 \mathrm{~cm}^{-1}$ to convolute the stick spectrum.

As previously shown and consistently with the experiments, theory predicts that the most stable form of 3 a in gas phase corresponds to the zcc tautomer. Interestingly, going to DCM and DMSO leads to markedly different results (Table S23). Indeed, unsurprisingly, the more polar is the solvent, the more the "z-heavy" structures are stabilized. Indeed, in DCM (DMSO), theory predicts that the $\mathbf{z z c}(\mathbf{z z z})$ form is the most stable one. The theoretical spectra of these three species are given in Figures 8 and $S_{59}$ and one notices that the long-wavelength absorption band presents a nearly equal position in zcc, zzc and zzz, whereas its intensity is roughly proportional to the ratio of zwitterionic rings. The lowest electronic transitions for these three species have been characterized (Figure 9). The long-wavelength bright states (> 550 $\mathrm{nm}$ ) are localized on the zwitterionic part(s) for the three tautomers of 3 a, whereas the canonical moieties are related to absorption at higher energies (ca. $470 \mathrm{~nm}$ ). 

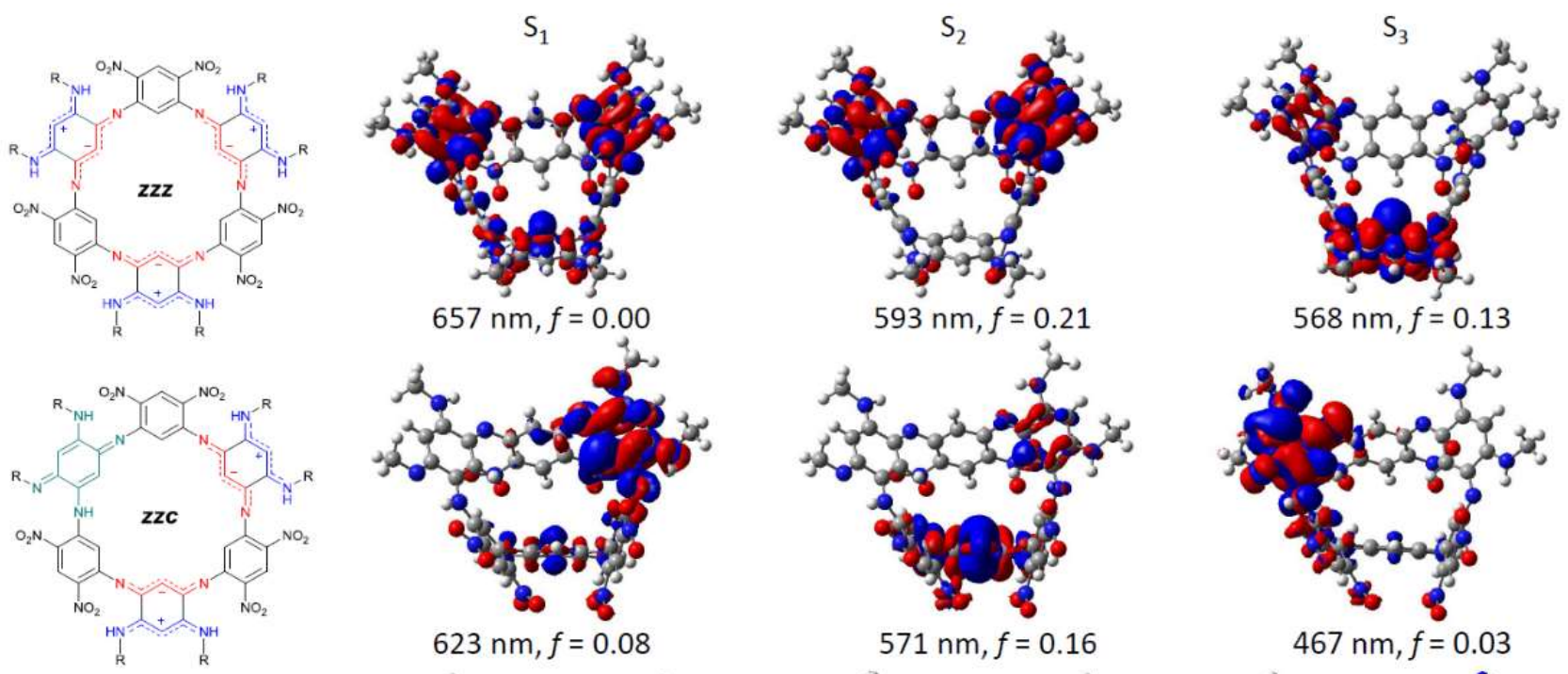

$571 \mathrm{~nm}, f=0.16$
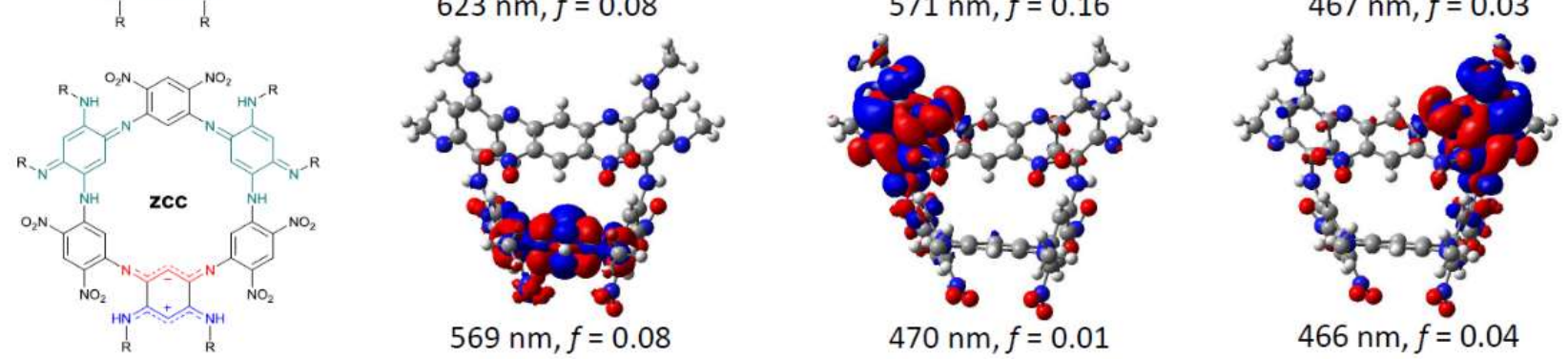

Figure 9. Representation of the TD-DFT electron density difference for the three lowest excited-states of $3 \mathbf{a}$ in three of its tautomeric forms. The blue and red regions respectively indicate decrease and increase of density upon photon absorption (contour threshold: $0.0008 \mathrm{au}$ ).

\section{CONCLUSION}

A new class of macrocycle, the azacalixquinarene family has been synthesized by partial oxidation of azacalixarenes. Single crystal structures highlighted that the cavity volume in four-membered macrocycles was higher than in the parent ACA due to the distortion brought by the imine functions. Importantly, [4]- and [6]-membered ACQs 2a and za presented one of their quinone cycle under zwitterionic electronic structure at the solid state. The nature of the $\mathrm{N}$-substituents influences the ground state of the quinone units, alkyl chains and strong electron-donating aryl moieties allowed to promote a zwitterionic character. The evolution of the absorption profiles observed in solution was rationalized by TD-DFT, highlighting the preponderance of zwitterionic units in polar environment. This fine, easily tunable balance between the presence of canonical and zwitterionic moieties within a same macrocyclic architecture paves the way to several sensing applications.

\section{EXPERIMENTAL SECTION \& THEORETICAL DETAILS}

Reagents. All reagents were purchased from Alfa-Aesar or Sigma-Aldrich and used as received. When heating was required, oil bathes were used. Column chromatography were performed using Silica 6oM (o.04-0.063 mm) purchased from Macherey-Nagel. Compounds $1 \mathbf{a},{ }^{35} \mathbf{6} \mathbf{a}$ and $\mathbf{7 a},{ }^{30} \mathbf{6 b}-\mathbf{c}$ and $\mathbf{7 b}-\mathbf{c},{ }^{34} \mathbf{8} \mathbf{a}^{24}$ were prepared following previously reported protocols.

Analytical methods and apparatus. NMR spectra were recorded on a JEOL ECS40o NMR spectrometer at room temperature, otherwise noted. NMR chemical shifts are given in ppm $(\delta)$ relative to $\mathrm{Me}_{4} \mathrm{Si}$ with solvent resonances used as internal standards $\left(\mathrm{CDCl}_{3}: 7.26 \mathrm{ppm}\right.$ for ${ }^{1} \mathrm{H}$ and 77.2 for ${ }^{13} \mathrm{C}\left\{{ }^{1} \mathrm{H}\right\}$; Acetone- $d_{6}: 2.05 \mathrm{ppm}$ for ${ }^{1} \mathrm{H}$ and 29.8 for ${ }^{13} \mathrm{C}\left\{{ }^{1} \mathrm{H}\right\}$; DMSO-d $\mathrm{d}_{6}$ : 2.50 ppm for ${ }^{1} \mathrm{H}$ and 39.5 for $\left.{ }^{13} \mathrm{C}\left\{{ }^{1} \mathrm{H}\right\}\right)$. UV-Vis-NIR absorption spectra were recorded on a VARIAN CARY 50 SCAN spectrophotometer at room temperature. NMR peak assignments were confirmed using a DEPT-135 method. Optical properties were recorded in spectrophotochemical grade solvents. HRMS (ESI) and MS (ESI) analyses were performed on a QStar Elite (Applied Biosystems SCIEX) or a SYNAPT G2 HDMS (Waters) spectrometers by the "Spectropole" of the Aix- 
Marseille University. These two instruments were equipped with an ESI or MALDI source spectrometer, and a TOF mass analyzer.

Single Crystal X-ray Diffraction. Suitable crystals for compounds $\mathbf{1 b}$, $\mathbf{2 a}$ and $\mathbf{3} \mathbf{a}$ were obtained from slow evaporation from acetonitrile, dichloromethane/acetonitrile and acetone respectively. They were mounted on a Rigaku Oxford Diffraction SuperNova diffractometer and measured at $203 \mathrm{~K}, 250 \mathrm{~K}$ and $150 \mathrm{~K}$ respectively, at the Cu radiation $(\lambda=1.54184 \AA)$. Data collection, reduction and multiscan ABSPACK correction were performed with CrysAlisPro (Rigaku Oxford Diffraction). Using Olex2 ${ }^{41}$ the structures were solved with the ShelXT ${ }^{42}$ structure solution program using Intrinsic Phasing and refined with ShelXL ${ }^{42}$ using least-square minimization. Crystals of $\mathbf{1 b}$ were found to be twins and all $\mathrm{H}$-atoms were determined experimentally. Structures of $\mathbf{2 a}$ and za revealed severe disordered for the octylamine moieties and hard constraints were applied during the refinement process. For both compounds the H-atoms for the central cycles and the amines were found experimentally except for atom N6 in 3a. The remaining H-atoms were introduced at geometrical positions and all $\mathrm{H}$-atoms were refined with riding coordinates to their parent atoms and with their Uiso parameters constraint to $1.2 \mathrm{Ueq}$ (parent atoms) for the $\mathrm{CH}, \mathrm{CH}_{2}$, and $\mathrm{NH}$ and $1.5 \mathrm{Ueq}$ (parent atoms) for the $\mathrm{CH}_{3}$. Compound $3 \mathrm{a}$ crystallized with 2 independent molecules in the asymmetric unit.

Electrochemistry. Cyclic voltammetry (CV) data were recorded using a BAS 100 (Bioanalytical Systems) potentiostat and the BASiooW software (v2.3). All the experiments were conducted under an argon atmosphere in a standard onecompartment using a three electrodes setup: a Pt working electrode $(\varnothing=1.6 \mathrm{~mm})$, a Pt counter electrode and an $\mathrm{Ag} / \mathrm{AgCl}$ reference electrode (filled with a $3 \mathrm{M} \mathrm{NaCl}$ solution). Tetra- $n$-butylammonium hexafluorophosphate ([TBA][PF $]$ ) was used as supporting electrolyte $\left(10^{-1} \mathrm{M}\right)$, with a concentration of the electro-active compound $c a$. $10^{-3} \mathrm{M}$. The reference electrode was calibrated using ferrocene $\left(\mathrm{E}^{\circ}\left(\mathrm{Fc} / \mathrm{Fc}^{+}\right)=0.46 \mathrm{~V} / \mathrm{SCE}(\mathrm{DCM}), 0.46 \mathrm{~V} / \mathrm{SCE}(\mathrm{DMF})\right){ }^{43}$ The scan rate was 100 $\mathrm{mV} / \mathrm{S}$. The solution was degassed using argon before recording each reductive scan, and the working electrode $(\mathrm{Pt}) \mathrm{was}$ polished before each scan recording.

DFT and TD-DFT Calculations. All calculations have been made with Gaussian-16, ${ }^{44}$ replacing the alkyl chains $\mathrm{C}_{8} \mathrm{H}_{17}$ by methyl groups in all the calculations for the sake of computational time. We have used the PBEo ${ }^{45}$ global hybrid functional for all our calculations. For compounds 1a-d and 2a, we have optimized the ground-state geometry with the 6$311++\mathrm{G}(2 \mathrm{~d}, 2 \mathrm{p})$ basis set, whereas larger compounds $\mathbf{2 b - c}$ and $3 \mathbf{3}$ have been optimized using the more compact 6-31G(d) atomic basis set. We verified the absence of imaginary frequencies by computing analytically the Hessian at the same level of theory. The excited-state calculations were performed with TD-DFT determined with the CAM-B3LYP ${ }^{46}$ exchange- $^{2}$ correlation functional in combination with the $6-311++G(2 \mathrm{~d}, 2 \mathrm{p})$ atomic basis set. This functional has been preferred to PBEo as several charge transfer states are considered in this study. The solvent effects were modeled through the wellknown Polarizable Continuum Model (PCM). ${ }^{47}$ Extra computational details are available in Section VII of the SI.

Synthesis of $N^{1}, N^{1}$-(4,6-dinitro-1,3-phenylene)bis $\left(N^{4}, N^{4}\right.$-dimethylbenzene-1,4-diamine) (4d). 1,5-difluoro-2,4dinitrobenzene ( $2 \mathrm{~g}, 9.80 \mathrm{mmol}, 1$ equiv.), $N, N$-dimethyl-p-phenylenediamine $(2.936 \mathrm{~g}, 21.56 \mathrm{mmol}, 2.5$ equiv. $)$ and $N, N-$ diisopropylethylamine $\left(5.12 \mathrm{~mL}, 29.40 \mathrm{mmol}, 3\right.$ equiv.) were heated at $145{ }^{\circ} \mathrm{C}$ for 2 hours. The reaction mixture was cooled to room temperature and the precipitate was filtered, washed several times with ethanol, $\mathrm{Et}_{2} \mathrm{O}$ and dried under vacuum to afford the product as a dark brown solid (3.94 g, 92\%). ${ }^{1} \mathrm{H}$ NMR $\left(\mathrm{CDCl}_{3}, 400 \mathrm{MHz}\right): \delta=9.55(\mathrm{br} \mathrm{s}, 2 \mathrm{H}, \mathrm{NH}), 9.31(\mathrm{~s}, 1 \mathrm{H}$, $\left.\mathrm{CH}), 6.99(\mathrm{~d}, J=8.9 \mathrm{~Hz}, 4 \mathrm{H}, \mathrm{CH}), 6.63(\mathrm{~d}, J=8.9 \mathrm{~Hz}, 4 \mathrm{H}, \mathrm{CH}), 6.30\left(\mathrm{~s},{ }_{1} \mathrm{H}, \mathrm{CH}\right), 2.94\left(\mathrm{~s}, 12 \mathrm{H}, \mathrm{N}\left(\mathrm{CH}_{3}\right)\right)_{2}\right) .{ }^{13} \mathrm{C}\left\{{ }^{1} \mathrm{H}\right\} \mathrm{NMR}$ $\left(\mathrm{CD}_{2} \mathrm{Cl}_{2}, 100 \mathrm{MHz}\right): \delta=149.6(\mathrm{C}), 148.2(\mathrm{C}), 129.6(\mathrm{CH}), 126.6(\mathrm{CH}), 126.3(\mathrm{C}), 125.3(\mathrm{C}), 109.5(\mathrm{CH}), 95.1(\mathrm{CH}), 40.7\left(\mathrm{CH}_{3}\right)$. HRMS (ESI+) calculated for $[\mathrm{M}+\mathrm{H}]^{+}: 437.1932\left(\mathrm{C}_{22} \mathrm{H}_{25} \mathrm{~N}_{6} \mathrm{O}_{4}^{+}\right)$, found: 437.1932 .

Synthesis of $N^{1}, N^{5}$-bis $(4$-(dimethylamino)phenyl)benzene-1,2,4,5-tetraamine tetrahydrochloride (5d). In a pressure bomb, compound $4 \mathrm{~d}\left(1 \mathrm{~g}, 2.29 \mathrm{mmol}, 1\right.$ equiv.) and $\mathrm{SnCl}_{2} \cdot 2 \mathrm{H}_{2} \mathrm{O}(4.136 \mathrm{~g}, 18.33 \mathrm{mmol}, 8$ equiv.) were dissolved in $10 \mathrm{~mL}$ of concentrated $\mathrm{HCl}(12 \mathrm{~N})$ and $10 \mathrm{~mL}$ of chloroform. The bomb was closed with a Teflon seal and the mixture was stirred at $60{ }^{\circ} \mathrm{C}$ for $15 \mathrm{~h}$. The resulting precipitate was filtered, washed several times with concentrated $\mathrm{HCl}(3 \times 20 \mathrm{~mL}), \mathrm{DCM}$, $\mathrm{Et}_{2} \mathrm{O}$ and finally dried under vacuum to afford the product as a withe powder $(739 \mathrm{mg}, 72 \%)$. The compound was stored at $-4{ }^{\circ} \mathrm{C}$ to prevent its oxidation to the corresponding quinone. ${ }^{1} \mathrm{H}$ NMR (DMSO- $\left.d_{6}, 400 \mathrm{MHz}\right): \delta=8.65(\mathrm{br} \mathrm{s}, 2 \mathrm{H}, \mathrm{NH}), 7.66$ $(\mathrm{d}, J=9.0 \mathrm{~Hz}, 4 \mathrm{H}, \mathrm{CH}), 7.41(\mathrm{~s}, 1 \mathrm{H}, \mathrm{CH}), 7.09(\mathrm{~s}, 1 \mathrm{H}, \mathrm{CH}), 7.06(\mathrm{~d}, J=9.0 \mathrm{~Hz}, 4 \mathrm{H}, \mathrm{CH}), 3.08\left(\mathrm{~s}, 12 \mathrm{H}, \mathrm{N}\left(\mathrm{CH}_{3}\right)_{2}\right) . \mathrm{No}{ }^{13} \mathrm{C}\left\{{ }^{1} \mathrm{H}\right\}$ NMR spectrum could be recorded owing to the poor stability in solution. HRMS (MALDI) calculated for $[\mathrm{M}+\mathrm{H}]^{+}: 376.2370$ $\left(\mathrm{C}_{22} \mathrm{H}_{28} \mathrm{~N}_{6}\right)$, found: 376.2360 .

Synthesis of $\quad N^{1}, N^{5}$-bis $\left(4\right.$-(dimethylamino)phenyl)- $N^{2}, N^{4}$-bis(5-fluoro-2,4-dinitrophenyl)benzene-1,2,4,5tetraamine (6d). Compound $5 \mathrm{~d}(500 \mathrm{mg}, 1.11 \mathrm{mmol}, 1$ equiv.) and 1,5-difluoro-2,4-dinitrobenzene (227 $\mathrm{g}, 1.11 \mathrm{mmol}, 1$ equiv.) were dissolved in $110 \mathrm{~mL}$ of acetonitrile. The solution was cooled to $\mathrm{o}^{\circ} \mathrm{C}$ and degassed under Argon bubbling for 
30 minutes. $\mathrm{N}, \mathrm{N}$-diisopropylethylamine $(1.55 \mathrm{~mL}, 8.90 \mathrm{mmol}, 8$ equiv.) was added dropwise to the solution. The reaction mixture was stirred for $2 \mathrm{~h}$ at $\mathrm{o}^{\circ} \mathrm{C}$, then warmed to $25^{\circ} \mathrm{C}$ and stirred for $15 \mathrm{~h}$. The crude solution was filtered to remove insoluble materials and the filtrate was evaporated under reduced pressure. The residue was subjected to column chromatography over silica gel using dichloromethane/ethyl acetate (9:1) as eluent to afford the product as a brown solid (125 mg, 30\%). $\mathrm{R}_{\mathrm{f}}$ : $0.47\left(\mathrm{SiO}_{2}\right.$, dichloromethane/ethyl acetate, 9:1). ${ }^{1} \mathrm{H} \mathrm{NMR}\left(\mathrm{CDCl}_{3}, 400 \mathrm{MHz}\right): \delta=9.37(\mathrm{br} \mathrm{s}, 2 \mathrm{H}, \mathrm{NH}), 9.11\left(\mathrm{~d}, J_{H-F}=\right.$ $7.6 \mathrm{~Hz}, 2 \mathrm{H}, \mathrm{CH}), 6.96(\mathrm{~s}, 1 \mathrm{H}, \mathrm{CH}), 6.92(\mathrm{~d}, J=8.8 \mathrm{~Hz}, 4 \mathrm{H}, \mathrm{CH}), 6.66\left(\mathrm{~d}, J_{\mathrm{H}-F}=13.1 \mathrm{~Hz}, 2 \mathrm{H}, \mathrm{CH}\right), 6.63-6.60(\mathrm{~m}, 5 \mathrm{H}, \mathrm{CH})$, $5.56\left(\mathrm{~s}, 2 \mathrm{H}, \mathrm{NH}_{2}\right), 2.90\left(\mathrm{~s}, 12 \mathrm{H}, \mathrm{N}\left(\mathrm{CH}_{3}\right)_{2}\right) \cdot{ }^{13} \mathrm{C}\left\{{ }^{1} \mathrm{H}\right\} \mathrm{NMR}\left(\mathrm{CDCl}_{3}, 400 \mathrm{MHz}, 100 \mathrm{MHz}\right): \delta=159.8\left(\mathrm{~d}, J_{\mathrm{C}-F}=271 \mathrm{~Hz}, \mathrm{C}\right), 149.4(\mathrm{~d}$, $\left.J_{C-F}=13 \mathrm{~Hz}, \mathrm{C}\right), 148.3(\mathrm{C}), 144.3(\mathrm{C}), 128.9(\mathrm{C}), 128.3(\mathrm{CH}), 127.9(\mathrm{C}), 127.6(\mathrm{CH}), 127.3(\mathrm{C}), 124.8(\mathrm{CH}), 113.3(\mathrm{CH}), 112.6(\mathrm{C})$, $103.7\left(\mathrm{~d}, J_{C-F}=27 \mathrm{~Hz}, \mathrm{CH}\right), 99.9(\mathrm{CH}), 40.8\left(\mathrm{CH}_{3}\right)$. HRMS (ESI+) calculated for $[\mathrm{M}+\mathrm{H}]^{+}: 745.2289\left(\mathrm{C}_{34} \mathrm{H}_{31} \mathrm{~N}_{10} \mathrm{O}_{8} \mathrm{~F}_{2}^{+}\right)$, found: 745.2288 .

Synthesis of $\quad(3 E, 6 E)-N^{1}-\left(5\right.$-fluoro-2,4-dinitrophenyl)-3-((5-fluoro-2,4-dinitrophenyl)imino)- $N^{4}-(3,4,5-$ trimethoxyphenyl)-6-((3,4,5-trimethoxyphenyl)imino)cyclohexa-1,4-diene-1,4-diamine (1b). To a solution of compound 6 b (100 mg, $0.119 \mathrm{mmol}, 1$ equiv.) in $3 \mathrm{~mL}$ of degassed chloroform was added 2,3-dichloro-5,6-dicyano-1,4benzoquinone ( $27 \mathrm{mg}, 0.119 \mathrm{mmol}, 1$ equiv.) and the mixture was stirred at $25^{\circ} \mathrm{C}$ for 30 minutes. After concentration under reduced pressure, the crude residue was purified by column chromatography over silica gel using dichloromethane/ethyl acetate (9:1) as eluent. The obtained compound was finally passed through a basic activated alumina pad (Brockmann I) via DCM to afford the product as a dark solid $(72 \mathrm{mg}, 72 \%)$. Rf: $0.70\left(\mathrm{SiO}_{2}\right.$, dichloromethane/ ethyl acetate, 9:1). ${ }^{1} \mathrm{H}$ NMR $\left(\mathrm{DMSO}_{6}, 400 \mathrm{MHz}\right): \delta=9.71(\mathrm{br} \mathrm{s}, 2 \mathrm{H}, \mathrm{NH}), 8.91\left(\mathrm{~d}, J_{\mathrm{H}-\mathrm{F}}=7.5 \mathrm{~Hz}, 2 \mathrm{H}, \mathrm{CH}\right), 7.8 \mathrm{o}\left(\mathrm{d}, J_{\mathrm{H}-\mathrm{F}}=12.7 \mathrm{~Hz}, 2 \mathrm{H}, \mathrm{CH}\right), 6.65(\mathrm{~s}, 1 \mathrm{H}$, $\mathrm{CH}), 6.43(\mathrm{~s}, 4 \mathrm{H}, \mathrm{CH}), 6.34(\mathrm{~s}, 1 \mathrm{H}, \mathrm{CH}), 3.69\left(\mathrm{~s}, 12 \mathrm{H}, \mathrm{OCH}_{3}\right), 3.62\left(\mathrm{~s}, 6 \mathrm{H}, \mathrm{OCH}_{3}\right) .{ }^{13} \mathrm{C}\left\{{ }^{1} \mathrm{H}\right\} \mathrm{NMR}\left(\mathrm{DMSO}-d_{6}, 100 \mathrm{MHz}\right): \delta=$ $157.8\left(\mathrm{~d}, J_{C-F}=270 \mathrm{~Hz}, \mathrm{C}\right), 153.1(\mathrm{C}), 148.1(\mathrm{C}), 147.6(\mathrm{C}), 146.4(\mathrm{C}), 140.0(\mathrm{C}), 134.8(\mathrm{C}), 134.1(\mathrm{C}), 130.8(\mathrm{C}), 125.5(\mathrm{CH}), 110.4$ $\left(\mathrm{d}, J_{C-F}=27 \mathrm{~Hz}, \mathrm{CH}\right), 102.3(\mathrm{CH})$, 99.o $(\mathrm{CH}), 91.8(\mathrm{CH})$, 60.o $\left(\mathrm{OCH}_{3}\right), 55.8\left(\mathrm{OCH}_{3}\right)$. HRMS (ESI+) calculated for [M+H] $]^{+}$: 837.1922 $\left(\mathrm{C}_{36} \mathrm{H}_{31} \mathrm{~F}_{2} \mathrm{~N}_{8} \mathrm{O}_{14}{ }^{+}\right)$, found: 837.1920.

Synthesis of $\quad(3 E, 6 E)-N^{1}$-(5-fluoro-2,4-dinitrophenyl)-3-((5-fluoro-2,4-dinitrophenyl)imino)- $N^{4}-(3-$ (trifluoromethyl)phenyl)-6-((3-(trifluoromethyl)phenyl)imino)cyclohexa-1,4-diene-1,4-diamine (1c). To a solution of compound 1c (100 mg, $0.126 \mathrm{mmol}, 1$ equiv.) in $2 \mathrm{~mL}$ of degassed tetrahydrofuran was added dropwise 2,3-dichloro-5,6dicyano-1,4-benzoquinone $(28.7 \mathrm{mg}, 0.126 \mathrm{mmol}, 1$ equiv.) in $2 \mathrm{~mL}$ of degassed tetrahydrofuran and the mixture was stirred at room temperature for $4 \mathrm{~h}$. After concentration under reduced pressure, the crude residue was washed with ethanol and diethyl ether to afford the product as a brown solid (8o mg, 8o\%). ${ }^{1} \mathrm{H}$ NMR (DMSO- $\left.d_{6}, 400 \mathrm{MHz}\right): \delta=9.97$ (br s, $2 \mathrm{H}, \mathrm{NH}), 8.93\left(\mathrm{~d}, J_{H-F}=7.2 \mathrm{~Hz}, 2 \mathrm{H}, \mathrm{CH}\right), 7.82\left(\mathrm{~d}, J_{\mathrm{H}-\mathrm{F}}=12.6 \mathrm{~Hz}, 2 \mathrm{H}, \mathrm{CH}\right), 7.65-7.35(\mathrm{~m}, 8 \mathrm{H}, \mathrm{CH}), 6.72(\mathrm{~s}, 1 \mathrm{H}, \mathrm{CH}), 6.13(\mathrm{~s}$, $1 \mathrm{H}, \mathrm{CH}$ ). Compound was too insoluble to record a $\left.{ }^{13} \mathrm{C}^{1} \mathrm{H}\right\}$ NMR spectrum. HRMS (ESI+) calculated for $[\mathrm{M}+\mathrm{H}]^{+}: 793.1036$ $\left(\mathrm{C}_{32} \mathrm{H}_{17} \mathrm{~F}_{8} \mathrm{~N}_{8} \mathrm{O}_{8}^{+}\right)$, found: 793.1041.

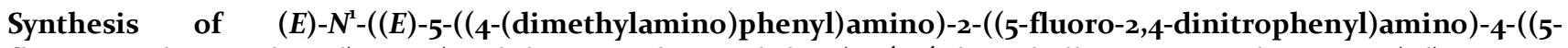
fluoro-2,4-dinitrophenyl)imino)cyclohexa-2,5-dien-1-ylidene)- $N^{4}, N^{4}$-dimethylbenzene-1,4-diamine (1d). To a solution of compound $\mathbf{6 d}$ (100 mg, $0.134 \mathrm{mmol}, 1$ equiv.) in $2 \mathrm{~mL}$ of degassed tetrahydrofuran was added 2,3-dichloro-5,6dicyano-1,4-benzoquinone ( $31 \mathrm{mg}$, $0.134 \mathrm{mmol}, 1$ equiv.) in $2 \mathrm{~mL}$ of degassed tetrahydrofuran and the mixture was stirred at $25{ }^{\circ} \mathrm{C}$ for $1 \mathrm{~h}$. After concentration under reduced pressure, the crude residue was washed with ethanol, diethyl ether and pentane to afford the product as a green solid $(76 \mathrm{mg}, 76 \%)$. ${ }^{1} \mathrm{H}$ NMR (DMSO- $\left.d_{6}, 400 \mathrm{MHz}, 353 \mathrm{~K}\right): \delta=9.60(\mathrm{br} \mathrm{s}, 2 \mathrm{H}, \mathrm{NH})$, $8.89\left(\mathrm{~d}, J_{H-F}=7.9 \mathrm{~Hz}, 2 \mathrm{H}, \mathrm{CH}\right), 7.18-6.88(\mathrm{~m}, 6 \mathrm{H}, \mathrm{CH}), 6.78\left(\mathrm{~d}, J_{H-F}=14.3 \mathrm{~Hz}, 2 \mathrm{H}, \mathrm{CH}\right), 6.75-6.60(\mathrm{~m}, 4 \mathrm{H}, \mathrm{CH}), 2.85(\mathrm{~s}$, $\left.12 \mathrm{H}, \mathrm{N}\left(\mathrm{CH}_{3}\right)_{2}\right)$. Compound was too insoluble to record a ${ }^{13} \mathrm{C}\left\{{ }^{1} \mathrm{H}\right\}$ NMR spectrum. HRMS (ESI+) calculated for [M+H $]^{+}$: 743.2132 $\left(\mathrm{C}_{34} \mathrm{H}_{29} \mathrm{~N}_{10} \mathrm{O}_{8} \mathrm{~F}_{2}^{+}\right)$, found: 743.2130.

Synthesis of ACQ 2a. To a solution of ACA 7a (50 mg, $0.047 \mathrm{mmol}, 1$ equiv.) in $2 \mathrm{~mL}$ of degassed chloroform was added 2,3-dichloro-5,6-dicyano-1,4-benzoquinone (22 mg, 0.095 mmol, 2 equiv.) and the mixture was stirred at $25{ }^{\circ} \mathrm{C}$ for $1 \mathrm{~h}$. After concentration under reduced pressure, the crude residue was purified by column chromatography over silica gel using dichloromethane as eluent to afford the product as a brown-green solid $(41 \mathrm{mg}, 82 \%)$. $\mathrm{R}_{\mathrm{f}}$ : o.8o ( $\mathrm{SiO}_{2}$, dichloromethane). ${ }^{1} \mathrm{H}$ NMR $\left(\mathrm{CDCl}_{3}, 400 \mathrm{MHz}\right): \delta=8.91(\mathrm{~s}, 2 \mathrm{H}, \mathrm{CH}), 8.45$ (br s, $\left.4 \mathrm{H}, \mathrm{NH}\right), 6.92(\mathrm{~s}, 2 \mathrm{H}, \mathrm{CH}), 6.14(\mathrm{~s}, 2 \mathrm{H}, \mathrm{CH}), 5.46(\mathrm{~s}$, $2 \mathrm{H}, \mathrm{CH}), 3.38\left(\mathrm{t}, J=6.8 \mathrm{~Hz}, 8 \mathrm{H}, \mathrm{N}-\mathrm{CH}_{2}\right), 1.76$ (quint, $\left.J=7.2 \mathrm{~Hz}, 8 \mathrm{H}, \mathrm{CH}_{2}\right), 1.56-1.25\left(\mathrm{~m}, 4 \mathrm{oH}, \mathrm{CH}_{2}\right), 0.88(\mathrm{t}, J=7.0 \mathrm{~Hz}, 12 \mathrm{H}$, $\left.\mathrm{CH}_{3}\right) \cdot{ }^{13} \mathrm{C}\left\{{ }^{1} \mathrm{H}\right\}$ NMR $\left(\mathrm{CDCl}_{3}, 100 \mathrm{MHz}\right): \delta=152.5(\mathrm{C}), 148.8(\mathrm{C}), 147.9(\mathrm{C}), 134.3(\mathrm{C}), 126.1(\mathrm{CH}), 110.2(\mathrm{CH}), 89.8(\mathrm{CH}), 85.3$ $(\mathrm{CH})$, $45.5\left(\mathrm{~N}_{-} \mathrm{CH}_{2}\right), 31.8\left(\mathrm{CH}_{2}\right), 29.3\left(\mathrm{CH}_{2}\right), 29.2\left(\mathrm{CH}_{2}\right)$, 29.0 $\left(\mathrm{CH}_{2}\right), 27.2\left(\mathrm{CH}_{2}\right), 22.6\left(\mathrm{CH}_{2}\right), 14.1\left(\mathrm{CH}_{3}\right)$. HRMS (ESI+) calculated for $[\mathrm{M}+\mathrm{H}]^{+}: 1049.6295\left(\mathrm{C}_{56} \mathrm{H}_{81} \mathrm{~N}_{12} \mathrm{O}_{8}^{+}\right)$, found: 1049.6295 .

Synthesis of ACQ 2 b. To a solution of ACA $7 \mathbf{b}$ (50 mg, $0.039 \mathrm{mmol}, 1$ equiv.) in $2 \mathrm{~mL}$ of degassed chloroform was added 2,3-dichloro-5,6-dicyano-1,4-benzoquinone (18 mg, 0.039 mmol, 2 equiv.) and the mixture was stirred at $25{ }^{\circ} \mathrm{C}$ for 30 minutes. After concentration under reduced pressure, the particularly insoluble residue was purified by flash column chromatography over silica gel using dichloromethane/acetone (9:1) as eluent to afford the product as a green solid (26 
mg, 52\%). $\mathrm{R}_{\mathrm{f}}$ : $0.40\left(\mathrm{SiO}_{2}\right.$, dichloromethane/acetone, 9:1). ${ }^{1} \mathrm{H}$ NMR (DMSO-d, $\left.400 \mathrm{MHz}\right): \delta=9.54(\mathrm{br} \mathrm{s}, 4 \mathrm{H}, \mathrm{NH}), 8.95$ (br s, $2 \mathrm{H}, \mathrm{CH}$ ), 7.55 (br s, $2 \mathrm{H}, \mathrm{CH}$ ), 7.11 (br s, $2 \mathrm{H}, \mathrm{CH}), 6.40$ (br s, $8 \mathrm{H}, \mathrm{CH}), 6.34$ (br s, $2 \mathrm{H}, \mathrm{CH}), 3.67$ (br s, $\left.24 \mathrm{H}, \mathrm{OCH}_{3}\right), 3.67$ (br s, ${ }_{12} \mathrm{H}, \mathrm{OCH}_{3}$ ). Compound was too insoluble to record a ${ }^{13} \mathrm{C}\left\{{ }^{1} \mathrm{H}\right\}$ NMR spectrum. HRMS (ESI+) calculated for $[\mathrm{M}+2 \mathrm{H}]^{2+}$ : $633.1940\left(\mathrm{C}_{60} \mathrm{H}_{58} \mathrm{~N}_{12} \mathrm{O}_{20}{ }^{2+}\right)$, found: 633.1940.

Synthesis of ACQ 2c. To a solution of compound 7c ( $80 \mathrm{mg}$, $0.068 \mathrm{mmol}, 1$ equiv.) in $2.5 \mathrm{~mL}$ of degassed tetrahydrofuran was added dropwise 2,3-dichloro-5,6-dicyano-1,4-benzoquinone (30.72 $\mathrm{mg}, 0.136 \mathrm{mmol}$, 2 equiv.) in $2.5 \mathrm{~mL}$ of degassed tetrahydrofuran and the mixture was stirred at $25^{\circ} \mathrm{C}$ for $19 \mathrm{~h}$. After concentration under reduced pressure, the crude residue was washed with ethanol and was purified by flash column chromatography over neutral aluminium oxide using dichloromethane/acetone (95:5) as eluent to afford the product as a brown solid (31 mg, 38\%). $\mathrm{R}_{\mathrm{f}}$ : 0.48 ( $\mathrm{SiO}_{2}$, dichloromethane/petroleum ether, 7:3). ${ }^{1} \mathrm{H}$ NMR (DMSO- $\left.d_{6}, 400 \mathrm{MHz}\right): \delta=9.80$ (br s, $\left.4 \mathrm{H}, \mathrm{NH}\right), 8.97(\mathrm{~s}, 2 \mathrm{H}, \mathrm{CH}), 7.62-7.38(\mathrm{~m}$, $18 \mathrm{H}, \mathrm{CH}), 7.20(\mathrm{~s}, 2 \mathrm{H}, \mathrm{CH}), 6.12(\mathrm{~s}, 2 \mathrm{H}, \mathrm{CH})$. Compound was too insoluble to record a ${ }^{13} \mathrm{C}\left\{{ }^{1} \mathrm{H}\right\}$ NMR spectrum. HRMS (ESI+) calculated for $[\mathrm{M}+\mathrm{H}]^{+}: 1177.2034\left(\mathrm{C}_{52} \mathrm{H}_{29} \mathrm{~F}_{12} \mathrm{~N}_{12} \mathrm{O}_{8}^{+}\right)$, found: 1177.2046.

Synthesis of ACQ 3a. To a solution of ACA 8 a (10 mg, $0.006 \mathrm{mmol}, 1$ equiv.) in $2 \mathrm{~mL}$ of degassed chloroform was added 2,3-dichloro-5,6-dicyano-1,4-benzoquinone $\left(4.3 \mathrm{mg}\right.$, $0.018 \mathrm{mmol}, 3$ equiv.) and the mixture was stirred at $25{ }^{\circ} \mathrm{C}$ for 30 minutes. After concentration under reduced pressure, the crude residue was purified by flash column chromatography over silica gel using dichloromethane as eluent to afford the product as a green solid ( $9 \mathrm{mg}$, 90\%). Note that column purification had to be performed quickly since degradation of the compound was observed on silica gel. $\mathrm{R}_{\mathrm{f}}: 0.74\left(\mathrm{SiO}{ }_{2}\right.$, dichloromethane). ${ }^{1} \mathrm{H}$ NMR (acetone- $\left.d_{6}, 400 \mathrm{MHz}\right): \delta=8.69$ (br s, $\left.2 \mathrm{H}\right), 6.67$ (br s, $\left.2 \mathrm{H}\right), 5.78(\mathrm{br} \mathrm{s}, 2 \mathrm{H}), 3.56\left(\mathrm{~m}, 12 \mathrm{H}, \mathrm{NCH}_{2}\right)$, $1.81\left(\mathrm{~m}, 12 \mathrm{H}, \mathrm{CH}_{2}\right), 1.50\left(\mathrm{~m}, 12 \mathrm{H}, \mathrm{CH}_{2}\right), 1.29\left(\mathrm{~m}, 48 \mathrm{H}, \mathrm{CH}_{2}\right), 0.89\left(\mathrm{t}, J=6.9 \mathrm{~Hz}, 18 \mathrm{H}, \mathrm{CH}_{3}\right)$. Quinoid units meet relaxation issues that yield uncomplete or unresolved NMR signals. ${ }^{1} \mathrm{H}$ NMR spectrum recorded in DMSO- $d_{6}$ at $353 \mathrm{~K}$ reveals the missing signals (see ESI) No ${ }^{13} \mathrm{C}\left\{{ }^{1} \mathrm{H}\right\}$ NMR spectrum could be recorded due to poorly resolved signals and poor solubility. HRMS (ESI+) calculated for $[\mathrm{M}+2 \mathrm{H}]^{2+}: 787.4739\left(\mathrm{C}_{84} \mathrm{H}_{122} \mathrm{~N}_{18} \mathrm{O}_{12}{ }^{2+}\right)$, found: 787.4737 .

Synthesis of compound ACP-C8 $\left(\mathbf{R}=\mathbf{C}_{\mathbf{8}} \mathbf{H}_{\mathbf{1 7}}\right)$ from ACQ $2 \mathrm{a}$. In a Schlenk tube, a solution of compound $2 \mathrm{a}$ ( $35 \mathrm{mg}$, o.033 mmol, 1 equiv.) in tetrahydrofuran $(15 \mathrm{~mL})$ was added by $5 \mathrm{wt} . \% \mathrm{Pd} / \mathrm{C}(21 \mathrm{mg}$, 0.010 mmol, $30 \mathrm{~mol} . \%)$, and hydrazine monohydrate $\left(203 \mu \mathrm{L}, 4.169 \mathrm{mmol}, 125\right.$ equiv.) and the mixture was stirred for $48 \mathrm{~h}$ at $80^{\circ} \mathrm{C}$. Then it was cooled to room temperature, concentrated under reduced pressure, and the residue was dissolved in $3 \mathrm{~mL}$ of methanol (solution instantaneously turned green, revealing the oxidation of azacalixarene to azacalixphyrin). The solution was bubbled with air for $16 \mathrm{~h}$ at $25^{\circ} \mathrm{C}$, then filtered on a Celite (AW) pad which was rinsed with $\mathrm{MeOH}$. The filtrate was evaporated and the solid was taken up in a mixture of dichloromethane and acetone, sonicated for few minutes, filtered and the solid was finally washed with acetonitrile, dichloromethane, diethyl ether and pentane to afford the product as a green powder (30 mg, 97\%). MS (ESI+) calculated for $[\mathrm{M}+2 \mathrm{H}]^{2+}: 464.4\left(\mathrm{C}_{56} \mathrm{H}_{88} \mathrm{~N}_{12}{ }^{2+}\right)$, found: 464.6 ; calculated for $[\mathrm{M}+\mathrm{H}]^{+}: 927.7\left(\mathrm{C}_{56} \mathrm{H}_{87} \mathrm{~N}_{12}{ }^{2+}\right)$, found: 927.8. NMR analysis and absorption spectra were identical to previously reported ones. ${ }^{30}$

\section{ASSOCIATED CONTENT}

Additional synthetic details, $1 \mathrm{H}$ and ${ }_{13} \mathrm{C}\left\{{ }^{1} \mathrm{H}\right\}$ NMR spectra, HRMS spectra, crystal data and structures refinements for compounds $\mathbf{1 b}, \mathbf{2 a}$ and $\mathbf{3 a}$, additional absorption spectra, cyclic voltammograms, theoretical calculations. The Supporting Information is available free of charge on the ACS Publications website at DOI: XXX.

\section{AUTHOR INFORMATION}

\section{Corresponding Authors}

* S.P.: pascal@cinam.univ-mrs.fr

* D.J.: Denis.Jacquemin@univ-nantes.fr.

*O.S.: olivier.siri@univ-amu.fr

\section{ORCID}

Simon Pascal: oooo-ooo1-8387-494X Lucien Lavaud: oooo-ooo1-8445-2159 Gabriel Canard: oooo-0002-3572-9091 Michel Giorgi: oooo-0oo2-4367-1985 Denis Jacquemin: 0ooo-0002-4217-0708 Olivier Siri: oooo-ooo1-9747-3813

\section{AKNOWLEDGEMENTS}


The authors thank the ANR for support in the framework of the EMA grant. We thank Joachim Galiana (Marseille) for his help in synthesizing macrocycle 3a. This research used resources of (i) the GENCI-CINES/ IDRIS; (ii) Centre de Calcul Intensif des Pays de Loire; (iii) a local Troy cluster and (iv) HPC resources from ArronaxPlus (Grant No. ANR-11-EQPX-ooo4 funded by the French National Agency for Research). Spectropole of Aix-Marseille University is acknowledged for mass spectrometry.

\section{REFERENCES}

(1) Gutsche, C. D., Calixarenes: An Introduction: Edition 2. RSC Publishing: 2008.

(2) Neri, P.; Sessler, J. L.; Wang, M.-X., Calixarenes and Beyond. Springer: 2016.

(3) König, B.; Fonseca, Maria H., Heteroatom-Bridged Calixarenes. Eur. J. Inorg. Chem. 2ooo, 2000 (11), $2303-2310$.

(4) Wang, M.-X., Heterocalixaromatics, new generation macrocyclic host molecules in supramolecular chemistry. Chem.

Commun. 2008, (38), 4541-4551.

(5) Tsue, H.; Ishibashi, K.; Tamura, R., Azacalixarene: A New Class in the Calixarene Family. Springer: 2007.

(6) Graubaum, H.; Lutze, G.; Tittelbach, F.; Bartoszek, M., Neue Azacyclophane aus Cyanurchlorid und Diaminen. J. Prakt. Chem. 1995, $337(1), 401-404$.

(7) Graubaum, H.; Lutze, G.; Costisella, B., Polyazacalix[5]arene - Synthese und NMR-Untersuchungen. J. Prakt. Chem. 1997, 339 (1), 266-271.

(8) Graubaum, H.; Lutze, G.; Costisella, B.; zur Linden, B., Polyazacalix[6]arene - Synthese und NMR-Untersuchungen. J. Prakt. Chem. 1997, 339 (1), 672-674.

(9) Niikura, K.; V. Anslyn, E., Azacalixarene: synthesis, conformational analysis, and recognition behavior toward anions. J. Chem. Soc., Perkin Trans. 2 1999, (12), 2769-2775.

(10) Ito, A.; Ono, Y.; Tanaka, K., N-Methyl-Substituted Aza[ın]metacyclophane:? Preparation, Structure, and Properties. J. Org. Chem. 1999, 64 (22), 8236-8241.

(11) Xue, M.; Chen, C.-F., Triptycene-Derived N(H)-Bridged Azacalixarenes: Synthesis, Structure, and Encapsulation of Small Neutral Molecules in the Solid State. Org. Lett. 2009, 11 (22), 5294-5297.

(12) Xue, M.; Chen, C.-F., Aromatic single-walled organic nanotubes self-assembled from NH-bridged azacalix[2]triptycene[2]pyridine. Chem. Commun. 2011, 47 (8), 2318-2320.

(13) Miyazaki, Y.; Kanbara, T.; Yamamoto, T., Preparation of new type of azacalixarene, azacalix[n](2,6)pyridine. Tetrahedron Lett. 2002, 43 (44), 7945-7948.

(14) Suzuki, Y.; Yanagi, T.; Kanbara, T.; Yamamoto, T., Preparation of N-(p-Tolyl)azacalix[n](2,6)pyridines Constructed of Various Numbers of the Recurring Unit. Synlett 2005, 2005 (02), 263-266.

(15) Yao, B.; Wang, Z.-L.; Zhang, H.; Wang, D.-X.; Zhao, L.; Wang, M.-X., Cu(ClO4)2-Mediated Arene C-H Bond Halogenations of Azacalixaromatics Using Alkali Metal Halides as Halogen Sources. J. Org. Chem. 2012, 77 (7), 3336-3340.

(16) Yao, B.; Liu, Y.; Zhao, L.; Wang, D.-X.; Wang, M.-X., Designing a $\mathrm{Cu}(\mathrm{II})-\mathrm{ArCu}(\mathrm{II})-\mathrm{ArCu}(\mathrm{III})-\mathrm{Cu}(\mathrm{I}) \mathrm{Catalytic} \mathrm{Cycle:} \mathrm{Cu}(\mathrm{II})-$ Catalyzed Oxidative Arene C-H Bond Azidation with Air as an Oxidant under Ambient Conditions. J. Org. Chem. 2014, 79 (22), 1113911145 .

(17) Yang, C.; Wu, W.-D.; Zhao, L.; Wang, M.-X., Macrocyclic Aryl-Nickel(II) Complexes: Synthesis, Structure, and Reactivity Studies. Organometallics 2015, 34 (20), 5167-5174.

(18) Liu, Y.; Zhang, Q.; Guo, Q.-H.; Wang, M.-X., Synthesis of Functionalized Azacalix[1]arene[3]pyridine Macrocycles from Cu(II)Mediated Direct Amination Reactions of Arene through High Valent Arylcopper(III) Intermediates. J. Org. Chem. 2016, 81 (21), 1040410410 .

(19) Liu, Y.; Long, C.; Zhao, L.; Wang, M.-X., Functionalization of Azacalixaromatics by Cu(II)-Catalyzed Oxidative Cross-Coupling Reaction between the Arene C-H Bond and Boronic Acids. Org. Lett. 2016, 18 (19), 5078-5081.

(20) Wang, F.; Zhao, L.; You, J.; Wang, M.-X., Synthesis of trifluoromethylthiolated azacalix[1]arene[3]pyridines from the Cu(ii)mediated direct trifluoromethylthiolation reaction of arenes via reactive arylcopper(iii) intermediates. Org. Chem. Front. 2016, 3 (7), $880-886$.

(21) Tsue, H.; Ishibashi, K.; Tokita, S.; Takahashi, H.; Matsui, K.; Tamura, R., Azacalix[6]arene Hexamethyl Ether: Synthesis, Structure, and Selective Uptake of Carbon Dioxide in the Solid State. Chem. Eur. J. 20o8, 14 (20), 6125-6134.

(22) Tsue, H.; Ono, K.; Tokita, S.; Ishibashi, K.; Matsui, K.; Takahashi, H.; Miyata, K.; Takahashi, D.; Tamura, R., Spontaneous and Selective $\mathrm{CO}_{2}$ Sorption under Ambient Conditions in Seemingly Nonporous Molecular Crystal of Azacalix[5]arene Pentamethyl Ether. Org. Lett. 2011, 13 (3), 490-493.

(23) Fa, S.-X.; Wang, L.-X.; Wang, D.-X.; Zhao, L.; Wang, M.-X., Synthesis, Structure, and Fullerene-Complexing Property of Azacalix[6]aromatics. J. Org. Chem. 2014, 79 (8), 3559-3571.

(24) Chen, Z.; Canard, G.; Azarias, C.; Jacquemin, D.; Siri, O., Straightforward metal-free synthesis of an azacalix[6]arene forming a host-guest complex with fullerene C6o. N. J. Chem. 2017, 41 (13), 5284-5290.

(25) Canard, G.; Andeme Edzang, J.; Chen, Z.; Chessé, M.; Elhabiri, M.; Giorgi, M.; Siri, O., 1,3-Alternate TetraamidoAzacalix[4]arenes as Selective Anion Receptors. Chem. Eur. J. 2016, 22 (16), 5756-5766.

(26) Ito, A.; Ono, Y.; Tanaka, K., The Tetraaza[1.1.1.1]m,p,m,p-cyclophane Dication: A Triplet Diradical Having Two mPhenylenediamine Radical Cations Linked by Twisted Benzenes. Angew. Chem. Int. Ed. 2ooo, 39 (6), 1072-1075.

(27) Ito, A., Macrocyclic oligoarylamines as hole- and spin-containing scaffolds for molecule-based electronics. J. Mater. Chem. C 2016, 4 (21), 4614-4625.

(28) Chen, Z.; Giorgi, M.; Jacquemin, D.; Elhabiri, M.; Siri, O., Azacalixphyrin: The Hidden Porphyrin Cousin Brought to Light. Angew. Chem. Int. Ed. 2013, 52 (24), 6250-6254.

(29) Marchand, G.; Laurent, A. D.; Chen, Z.; Siri, O.; Jacquemin, D., Exceptional Stability of Azacalixphyrin and Its Dianion. J. Phys. Chem. A 2014, 118 (38), 8883-8888.

(30) Chen, Z.; Haddoub, R.; Mahé, J.; Marchand, G.; Jacquemin, D.; Andeme Edzang, J.; Canard, G.; Ferry, D.; Grauby, O.; Ranguis, A.; Siri, O., N-Substituted Azacalixphyrins: Synthesis, Properties, and Self-Assembly. Chem. Eur. J. 2016, 22 (49), 17820-17832. 
(31) Marchand, G.; Siri, O.; Jacquemin, D., Effects of chemical substitutions on the properties of azacalixphyrins: a first-principles study. Phys. Chem. Chem. Phys. 2016, 18 (39), 27308-27316.

(32) Marchand, G.; Giraudeau, P.; Chen, Z.; Elhabiri, M.; Siri, O.; Jacquemin, D., Understanding the tautomerism in azacalixphyrins. Phys. Chem. Chem. Phys. 2016, 18 (14), 9608-9615.

(33) Azarias, C.; Pascal, S.; Siri, O.; Jacquemin, D., Central substitution of azacalixphyrins: a strategy towards acidochromic NIR dyes. Phys. Chem. Chem. Phys. 2018, 20 (30), 20056-20069.

(34) Lavaud, L.; Pascal, S.; Metwally, K.; Gasteau, D.; Da Silva, A.; Chen, Z.; Elhabiri, M.; Canard, G.; Jacquemin, D.; Siri, O., Azacalixphyrins as NIR photoacoustic contrast agents. Chem. Commun. 2018, 54 (87), 12365-12368.

(35) Pascal, S.; Lavaud, L.; Azarias, C.; Canard, G.; Giorgi, M.; Jacquemin, D.; Siri, O., Controlling the canonical/zwitterionic balance through intramolecular proton transfer: a strategy for vapochromism. Mater. Chem. Front. 2018, 2 (9), 1618-1625.

(36) Konishi, H.; Hashimoto, S.; Sakakibara, T.; Matsubara, S.; Yasukawa, Y.; Morikawa, O.; Kobayashi, K., Synthesis and conformational properties of tetranitroazacalix[4]arenes. Tetrahedron Lett. 2009, 50 (6), 620-623.

(37) Vale, M.; Pink, M.; Rajca, S.; Rajca, A., Synthesis, Structure, and Conformation of Aza[1n]metacyclophanes. J. Org. Chem. 2oo8, $73(1), 27-35$.

(38) Fang, Y.-X.; Zhao, L.; Wang, D.-X.; Wang, M.-X., Synthesis, Structure and Metal Binding Property of Internally 1,3-AryleneBridged Azacalix[6]aromatics. J. Org. Chem. 2012, 77 (22), 10073-10082.

(39) Lavaud, L.; Chen, Z.; Elhabiri, M.; Jacquemin, D.; Canard, G.; Siri, O., Di- vs. tetra-substituted quinonediimines: a drastic effect on coordination chemistry. Dalton Trans. 2017, 46 (38), 12794-12803.

(40) Pascal, S.; Siri, O., Benzoquinonediimine ligands: Synthesis, coordination chemistry and properties. Coord. Chem. Rev. 2o17, 350 (Supplement C), 178-195.

(41) Dolomanov, O. V.; Bourhis, L. J.; Gildea, R. J.; Howard, J. A. K.; Puschmann, H., OLEX2: a complete structure solution, refinement and analysis program. J. Appl. Crystallogr. 2009, 42 (2), 339-341.

(42) Sheldrick, G., SHELXT - Integrated space-group and crystal-structure determination. Acta Crystallogr. A 2015 , 71 (1), 3-8.

(43) Connelly, N. G.; Geiger, W. E., Chemical Redox Agents for Organometallic Chemistry. Chem. Rev. 1996, 96 (2), $877-910$.

(44) M. J. Frisch, et al., Gaussian 16, revision A.03, Wallignford, CT, USA, 2016.

(45) Adamo, C.; Barone, V., Toward reliable density functional methods without adjustable parameters: The PBEo model. J. Chem. Phys. 1999, 110 (13), 6158-6169.

(46) Yanai, T.; Tew, D. P.; Handy, N. C., A new hybrid exchange-correlation functional using the Coulomb-attenuating method (CAM-B3LYP). Chem. Phys. Lett. 2004, 393 (1-3), 51-57.

(47) Tomasi, J.; Mennucci, B.; Cammi, R., Quantum Mechanical Continuum Solvation Models. Chem. Rev. 2005, 105 (8), $2999-3093$. 